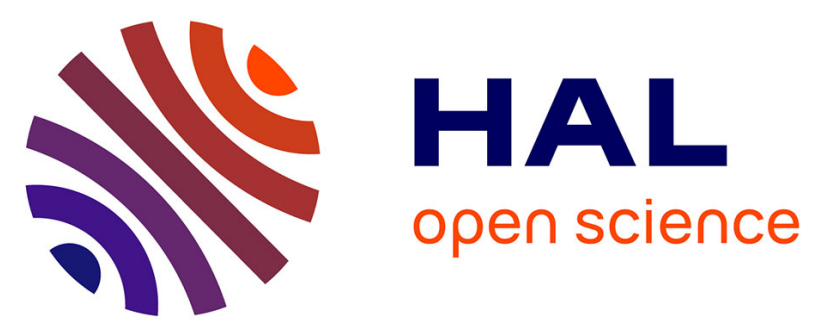

\title{
Exo70, a subunit of the exocyst complex, interacts with SnevhPrp19/hPso4 and is involved in pre-mRNA splicing
}

\author{
Hanna Dellago, Marlies Löscher, Paul Ajuh, Ursula Ryder, Christian
}

Kaisermayer, Regina Grillari-Voglauer, Klaus Fortschegger, Stefan Gross, Anna Gstraunthaler, Nicole Borth, et al.

\section{To cite this version:}

Hanna Dellago, Marlies Löscher, Paul Ajuh, Ursula Ryder, Christian Kaisermayer, et al.. Exo70, a subunit of the exocyst complex, interacts with SnevhPrp19/hPso4 and is involved in pre-mRNA splicing. Biochemical Journal, 2011, 438 (1), pp.81-91. 10.1042/BJ20110183 . hal-00612963

\section{HAL Id: hal-00612963 https://hal.science/hal-00612963}

Submitted on 2 Aug 2011

HAL is a multi-disciplinary open access archive for the deposit and dissemination of scientific research documents, whether they are published or not. The documents may come from teaching and research institutions in France or abroad, or from public or private research centers.
L'archive ouverte pluridisciplinaire HAL, est destinée au dépôt et à la diffusion de documents scientifiques de niveau recherche, publiés ou non, émanant des établissements d'enseignement et de recherche français ou étrangers, des laboratoires publics ou privés. 


\title{
EX070, A SUBUNIT OF THE EXOCYST COMPLEX, INTERACTS WITH SNEV HPRP19/HPSO4 AND IS INVOLVED IN PRE-MRNA SPLICING
}

Research article

\begin{abstract}
Hanna Dellago ${ }^{1^{*}}$, Marlies Löscher ${ }^{1^{\star}}$, Paul Ajuh ${ }^{2,3}$, Ursula Ryder $^{3}$, Christian Kaisermayer ${ }^{1}$, Regina Grillari-Voglauer ${ }^{1}$, Klaus Fortschegger ${ }^{1}$, Stefan Gross ${ }^{1}$, Anna Gstraunthaler ${ }^{1}$, Nicole Borth ${ }^{1}$, Frank Eisenhaber ${ }^{4,5,6}$, Angus I. Lamond ${ }^{3}$, and Johannes Grillari ${ }^{1}$
\end{abstract}

From ${ }^{1}$ Department of Biotechnology, University of Natural Resources and Life Sciences Vienna, Austria

${ }^{2}$ Current address: Dundee Cell Products Ltd, Dundee University Incubator, Dundee, Scotland, UK

${ }^{3}$ Department of Gene Expression and Regulation, University of Dundee, Scotland, UK

${ }^{4}$ Bioinformatics Institute (BII), Agency for Science, Technology and Research (A*STAR), 30 Biopolis Street, Singapore 138671

${ }^{5}$ Department of Biological Sciences (DBS), National University of Singapore (NUS), 8 Medical Drive, Singapore 117597

${ }^{6}$ School of Computater Engineering (SCE), Nanyang Technolo gical University (NTU), 50

Nanyang Drive, Singapore 637553

* authors contributed equally to this work

Running head: Exo70 and pre-mRNA splicing

Address correspondence to:

Johannes Grillari

Department of Biotechnology, University for Natural Resources and Applied Life Sciences Vienna, Muthgasse 18, A-1190 Vienna, Austria,

Phone: +431476546230

Fax: + 43-1-3697615

E-mail: johannes.grillari@boku.ac.at

Key words: Exocyst, Exo70, Prp19, SNEV, alternative splicing, protein interaction

Short title: Exo70 and splicing 


\section{SYNOPSIS}

The CDC5L complex is a spliceosomal subcomplex that also plays a role in DNA repair. The complex contains the splicing factor hPRP19 also known as SNEV or hPso4 which is involved in cellular life span regulation and proteasomal breakdown. In a recent large scale proteomics analysis for proteins associated with this complex, proteins involved in transcription, cell cycle regulation, DNA repair, the ubiquitin/proteasome system, chromatin remodelling, cellular aging, the cytoskeleton and trafficking, including 4 members of the exocyst complex, were identified. Here we report that Exo70 interacts directly with SNEVhPrp19/hPso4 and shuttles to the nucleus, where it associates with the spliceosome. We mapped the interaction site to the Nterminal 100 amino acids of Exo70, which interfere with pre-mRNA splicing in vitro. Furthermore, Exo70 influences the splicing of a model substrate as well as of its own premRNA in vivo. In addition, we found that Exo70 is alternatively spliced in a cell type and cell age dependent way. These results suggest a novel and unexpected role of Exo70 in nuclear mRNA splicing, where it might signal membrane events to the splicing apparatus. 


\section{INTRODUCTION}

In higher eukaryotes, the vast majority of protein-coding genes contain introns, which must be removed from pre-mRNA in a process called splicing. Splicing is carried out by the spliceosome, a highly dynamic multiple megadalton molecular machine. The spliceosome consists of 5 snRNPs called U1, U2, U4, U5 and U6, and a large number of non-snRNP splicing factors. For efficient splicing to take place, snRNPs and other splicing factors must associate on the pre-mRNA in a highly ordered manner, and several structural rearrangements are necessary before the spliceosome adopts its catalytically active composition (reviewed in [1]). Among the $>35$ non-snRNP proteins recruited during formation of the active spliceosome is the Prp19/Cdc5L complex. The mammalian Prp19/Cdc5L core complex consists of Prp19, also called SNEV ${ }^{\text {hPrp19/hPso4 }}$ in humans, Cdc5L, Pirg1, and Spf27. Recently, the molecular architecture of this complex has been elucidated [2]. Additional socalled Prp19/Cdc5L-related proteins physically interact with either SNEVhPrp19//Psso4 or Cdc5L, including the protein SKIP [3, 4].

We were able to confirm that SNEVhPrp19/hPso4 plays an essential role in splicing, by showing that SNEVhPrp19/hPso4 interacts with itself and that inhibition of this self interaction blocks spliceosome assembly [5]. Its necessity for pre-mRNA splicing might also explain why SNEV ${ }^{\text {Prp } 19 / h P s o 4}$ deletion is early embryonic lethal in mice [6]. Furthermore, by analysing directly interacting proteins we identified recently a novel pre-mRNA splicing factor termed Blom7 $\alpha$ [7].

In addition to its presence in the spliceosome, SNEV ${ }^{\mathrm{hPrp19} / \mathrm{hPs} 04}$ has been described as a DNA repair factor that is induced in response to DNA damaging agents and that together with CDC5L and WRN is necessary for repair of DNA interstrand cross-links [8]. It recruits the DNA repair factor Metnase to DNA double strand breaks [9]. Recently it was found that Cdc5L interacts with the major damage response mediator ATR and is necessary for activation of ATR downstream effectors [10]. Probably it is this activity that increases stress resistance and replicative life span upon SNEV ${ }^{\text {hPrp19/hPso4 }}$ overexpression in human endothelial cells [11].

SNEV ${ }^{\text {PPrp19/hPso4 }}$ also has catalytic activity as an E3 ubiquitin ligase in vitro [12] and directly interacts with the proteasome [13, 14]. In addition, SNEVhPrp19/hPso4 ubiquitinates Prp3, a component of the U4 snRNP. The modification of Prp3 with K63-linked ubiquitin chains increases its affinity for the U5 component Prp8 and thus stabilizs the U4/U6.U5 snRNP [15].

In an attempt to further elaborate on the multiple cellular roles of the Cdc5L/Prp19 complex, a large-scale pulldown from HeLa nuclear extracts using antibodies against CDC5L and against SKIP was performed recently [16]. Consistent with the known functions of the proteins we found, besides pre-mRNA splicing factors, proteins known to be involved in DNA repair, protein turnover by the proteasome, cell cycle regulation and cellular aging. Moreover, we identified proteins with functions not directly related to splicing like trafficking, chromatin remodeling, the cytoskeleton or protein folding and assembly. However, one novel interaction partner was identified that also came up in a recently performed yeast two-hybrid screening using SNEV ${ }^{\text {hPrp19/hPso4 }}$ as bait [7]: the exocyst subunit Ex070, also termed EXOC7. For Cdc5L and SKIP, additional exocyst components were found as interactors: Sec5 (or EXOC2), Sec8 (or EXOC4) and Sec10 (or EXOC5), as well as Sec13-like protein, a constituent of the endoplasmic reticulum and the nuclear pore complex that is required for vesicle biogenesis. These novel interactions were unexpected because the main function of the exocyst complex is vesicular transport, where it mediates the tethering and spatial targeting of post-Golgi vesicles to the plasma membrane. Up to now, only cytoplasmic localization has been observed for exocyst components, although the Sec13-like protein was already found to shuttle to the nucleus [17].

Here, we show a novel facet of Exo70. It is not only a direct and physical interactor of SNEV that shuttles between cytoplasm and the nucleus, we also present data that suggest a role for Exo70 in pre-mRNA splicing. Furthermore, we found previously unknown splicing isoforms of Exo70, which are differentially regulated in various tissues and during cellular aging. 


\section{MATERIALS AND METHODS}

\section{Construction of plasmids}

The coding sequence of SNEV ${ }^{\text {hPrp19/hPso4 }}$ was amplified by RT-PCR, therefore total RNA was prepared using Trizol reagent (Invitrogen). $1 \mathrm{\mu g}$ total RNA from human umbilical vein endothelial cells (HUVEC) was reverse transcribed using oligo(dT) ${ }_{25}$ primers, and standard PCR with the primers SNEV Ndel sense 5'- GTA CAC ATA TGT CCC TAA TCT GCT CC-3' and SNEV Smal antisense 5'-CAT TGA CCC GGG CAG GCT GTA GAA CTT GAG G-3' was performed. Exo70 and its truncated forms $C C$ and $\triangle C C$ were amplified by PCR from the clone isolated by yeast two-hybrid screening [7]. SNEV cDNA was ligated into pGADT7 and pGBKT7 for yeast two hybrid analysis, SNEVhPrp19/hPso4 and Exo70 cDNA into pEYFP-C1, -N1 and pECFP-C1,-N1 for FRET analyis. (Clontech Laboratories). Exo70 in pEGFP-N1 and -C1 were kindly provided by R. H. Scheller, Stanford University. For GST pull down assays SNEV ${ }^{\text {hPrp19/hPso4 }}$ was inserted into pGEX-6P-1 (Amersham Biosciences), while Exo70, CC and

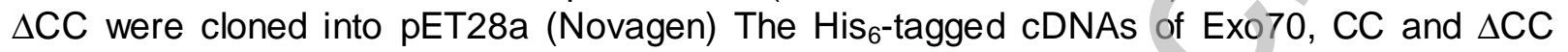
were cut and religated into $\mathrm{pCIneo} \mathrm{(Promega)} \mathrm{for} \mathrm{transient} \mathrm{mammalian} \mathrm{expression} \mathrm{as} \mathrm{well} \mathrm{as}$ into pET28a for recombinant protein expression in E. coli. For in vivo splicing assays, Exo70 was amplified from HeLa cDNA using the primers Exo70_start_EcoRI_long 5'- CCC TTT GAA TTC ATG ATT CCC CCA CAG GAG GC-3' and Exo70_stop_BamHI_long 5'- CCC TTT GGA TCC TCA GGC AGA GGT GTC G-3' and cloned into pEGFP-C2 by EcoRI and BamHI restriction sites. pMT-E1A was kindly provided by J. F. Caceres, MRC Human Genetics Unit, Western General Hospital, Edinburgh. All cDNAs contained in the genetic constructs were confirmed to contain no mutations by sequence analysis (IBL, Vienna, Austria). The $\mathrm{His}_{6}{ }^{-}$ SNEV ${ }^{\mathrm{hPrp} 19 / \mathrm{hPs}^{2}}$ containing plasmid for baculoviral expression was kindly provided by $\mathrm{S}$. Hatakeyama, Hokkaido University, Sapporo, Japan.

\section{Directed Yeast Two-Hybrid assay}

Screening for SNEV interacting proteins was performed using the MATCHMAKER GAL4 TwoHybrid System3 (Clontech Laboratories) according to the manufacturer's guidelines. As bait, pGBKT7-SNEV ${ }^{\mathrm{hPr} 19 / \mathrm{hPs} 04}$ was cotransformed into the yeast reporter strain AH109 together with human Exo70 and truncation mutants containing CC or $\triangle C C$ inserted into pGADT7. Yeast cotransformation was performed by the LiAc-method [18]. Interactions were confirmed on plates containing high stringency $4 \times$ drop out media (SD/-Leu/-Trp/-His/-Ade). Autoactivation of the constructs was excluded by transformation of plasmids alone and co-transformation with the respective empty vector plasmid.

\section{Recombinant protein expression and purification of His-Exo70 and generation of monoclonal antibodies}

The plasmids pET28a-Exo70, $-C C$ and $-\Delta C C$ were introduced into E. coli BL21LysDE. Bacteria were grown in $11 \mathrm{LB}$ broth containing $25 \mu \mathrm{g} / \mathrm{ml}$ kanamycin at $37^{\circ} \mathrm{C}$ on a shaker until an OD600 of 0,6 was reached. Thereupon recombinant protein expression was induced by addition of IPTG to a final concentration of $1 \mathrm{mM}$. and incubation at $37^{\circ} \mathrm{C}$ with shaking was continued for $4 \mathrm{~h}$. Bacteria were sonicated in lysis buffer $\left(50 \mathrm{mM} \mathrm{NaH}_{2} \mathrm{PO}_{4} ; 300 \mathrm{mM} \mathrm{NaCl}, 10\right.$ $\mathrm{mM}$ imidazole; $0.05 \%$ Tween $20 ; \mathrm{pH} 8.0$ ). His ${ }_{6}$-tagged proteins were purified under native conditions using $\mathrm{Ni}^{2+}$ NTA sepharose beads (Amersham Biosciences). Beads were washed thrice with wash buffer $\left(50 \mathrm{mM} \mathrm{NaH}_{2} \mathrm{PO}_{4} ; 300 \mathrm{mM} \mathrm{NaCl}, 20 \mathrm{mM}\right.$ imidazole, $0.05 \%$ Tween 20, $\mathrm{pH}$ 8.0). Bound proteins were eluted with elution buffer ( $50 \mathrm{mM} \mathrm{NaH}_{2} \mathrm{PO}_{4} ; 300 \mathrm{mM} \mathrm{NaCl}, 250$ $\mathrm{mM}$ imidazole, $0.05 \%$ Tween $20, \mathrm{pH}$ 8.0). Polyclonal sera and monoclonal antibodies were generated following our recently published protocol for SNEV [19]. The pGEX-6P-1-SNEV plasmid was transformed into E. coli BL21, and the fusion protein was expressed using Overnight Express Autoinduction System 1 (Novagen) and purified using the Micro Spin GST Purification Module (Amersham Biosciences). Recombinant proteins were dialysed against $20 \%$ glycerol in $1 \times$ PBS, aliquoted, snap frozen in liquid nitrogen and stored at $-80^{\circ} \mathrm{C}$. 


\begin{abstract}
Co-Immunoprecipitation (CoIP)
The purified $\mathrm{His}_{6}$-tagged Exo70 was immobilized on $\mathrm{Ni}^{2+}-\mathrm{NTA}$ agarose beads. In vitro translation of SNEVhPrp19/hPso4 was performed using TNT Quick Coupled Transcription/Translation System (Promega) and the pGBKT7 derived plasmid as template, resulting in a c-myc-tagged SNEV ${ }^{\mathrm{hPr} P 19 / \mathrm{hPs}^{2}}$. After mixing the in vitro translate with $\mathrm{His}_{6}$-tagged Exo70 and incubation at $37^{\circ} \mathrm{C}$ for 1 hour, precipitat ion was performed by addition of the $\mathrm{Ni}^{2+}-$ NTA agarose beads and incubation at room temperature for 3 hours in binding buffer $(20 \mathrm{mM}$ Tris-HCl pH 7.4, $140 \mathrm{mM} \mathrm{NaCl}, 10 \%$ v/v glycerol, $1 \mathrm{mM} \mathrm{CaCl}_{2}, 0.1 \%$ Triton $\mathrm{X}-100$ and Complete Protease-Inhibitor-Cocktail (Roche). After washing 4 times with binding buffer, the proteins were eluted by heating for $10 \mathrm{~min}$ in SDS sample buffer. After SDS-polyacrylamide gel electrophoresis (PAGE), proteins were detected by Western blotting using anti-c-myc antibody (Clontech Laboratories) and anti-mouse peroxidase conjugate as secondary antibody (Sigma-Aldrich).

For the GST pull-down assays equimolar amounts of the purified proteins were mixed and incubated for $2 \mathrm{~h}$ at $4^{\circ} \mathrm{C}$ in ColP-buffer $(200 \mathrm{mM} \mathrm{NaCl}, 25 \mathrm{mM}$ Tris- $\mathrm{HCl} \mathrm{pH} 7.4,0.5 \%$ Triton X100 ), followed by addition of glutathione sepharose 4B beads (Amersham Biosciences) equilibrated with ColP-buffer and $2 \mathrm{~h}$ incubation at $4^{\circ} \mathrm{C}$. The beads were washed thrice with CoIP-buffer, and proteins were eluted by heating for $10 \mathrm{~min}$ in SDS sample buffer. After SDSPAGE, precipitated SNEV ${ }^{\mathrm{hPrp1} 1 / \mathrm{hPs} 04}$ was detected using anti-4His antibody (Qiagen). GST was detected using anti-GST antibody (Amersham) and anti-goat peroxidase conjugate as secondary antibody (Sigma-Aldrich).
\end{abstract}

\title{
SDS PAGE and Western Blotting
}

Protein samples were separated on a NUPAGE 4-12\% Bis/Tris polyacrylamide gel (Invitrogen). Electrophoresis and blotting to PVDF membrane (Roth) were performed in accordance to the manufacturer's protocol (Invitrogen). After blocking with 3\% skim milk powder in PBS, the membranes were incubated with the primary antibodies followed by incubation with the appropriate secondary antibody.

Endogenous SNEV was detected using anti-SNEV_867 (from P. Ajuh) and goat anti-rabbit IgG peroxidase conjugate antibody as secondary antibody (Sigma). Endogenous Exo70 was detected by monoclonal anti-Exo70 antibody generated as described and anti-mouse lgG peroxidase conjugate antibody (Sigma).

To determine purity of subcellular fractionation, anti-Lamin $\mathrm{A} / \mathrm{C}$ rabbit polyclonal antibody and anti-GAPDH rabbit antibody (both Santa Cruz) were used in combination with Anti-Rabbit-IRDye 800 (from goat, $\mathrm{H}+\mathrm{L}$, Licor).

Detection was performed with ECL-Plus (AmershamBiosciences) and the Lumilmager (Roche Applied Science) or with the Odyssey Infrared Scanner (Licor), depending on the type of secondary antibody used.

\section{Cell culture}

HeLa cells were grown in RPMI 1640 (Biochrom) supplemented with $4 \mathrm{mM} \mathrm{L-glutamine} \mathrm{and}$ $10 \%$ Fetal calf serum (FCS). HEK293, HDF and MDCK cells were grown in DMEM/HAM's F12 1:1 (Biochrom) supplemented with $4 \mathrm{mM}$ L-glutamine and $10 \%$ FCS. HUVECs were grown in M199 medium (Biochrom) supplemented with $4 \mathrm{mM} \mathrm{L-glutamine,} \mathrm{15 \%} \mathrm{FCS,} 90 \mu \mathrm{g} / \mathrm{ml}$ Heparin and $200 \mu \mathrm{g} / \mathrm{ml}$ ECGS (Endothelial cell growth supplement). RPTEC were grown as described [20]. Cells were fixed for immunostaining after $6 \mathrm{~h}$ or overnight exposure to $10 \mathrm{pM}$ Leptomycin B (Calbiochem, Darmstadt, Germany). Cells are considered senescent after undergoing an irreversible growth arrest due to telomere shortening [21, 22]. HDF enter senescence around population doubling (PD) 60, HUVEC around PD 45-50 [23] and RPTEC around PD 20-25 [20]. Cells are considered "young" throughout the first half of their replicative life span. 


\section{Preparation of nuclear extracts}

Splicing competent nuclear extracts were prepared as described previously [24]. In brief, HeLa cells were harvested at around $80 \%$ confluence and washed twice with PBS. The cells were resuspended in buffer NE1 (10 mM Hepes $\mathrm{pH} 8.0,1.5 \mathrm{mM} \mathrm{MgCl} 2,10 \mathrm{mM} \mathrm{KCl}$, and 1 $\mathrm{mM}$ DTT) and incubated for $15 \mathrm{~min}$ on ice. Cells were passed through a $23 \mathrm{~g}$ syringe for 5 times. After centrifugation the pellet was resuspended in buffer NE2 (20 mM Hepes pH 8.0, $1.5 \mathrm{mM} \mathrm{MgCl}_{2}, 25 \%$ Glycerol, $420 \mathrm{mM} \mathrm{NaCl}, 0.2 \mathrm{mM}$ EDTA, $1 \mathrm{mM}$ DTT, $0.5 \mathrm{mM}$ PMSF). After centrifugation, the pellet was resuspended in NE2 and incubated on ice for 30 min. Nuclear debris was pelletted by centrifugation and supernatant dialysed against NE2.

\section{Fluorescence Resonance Energy Transfer (FRET)}

SNEV ${ }^{\text {Prp } 19 / h P s o 4}$ and Exo70 inserted in pECFP-N1, pECFP-C1 and pEYFP-N1, pEYFP-C1, respectively, were transiently cotransfected into COS-1 cells by lipofectamine 2000 (Invitrogen) according to the manufacturer's guidelines. After $24 \mathrm{~h}$ FRET images from living cells were generated by the MicroFRET method according to Youvan [25] and as already published before $[5,7,13]$. Photos were captured on a Nikon Diaphot TMD microscope with a cooled charge coupled device camera (Kappa $\mathrm{GmbH}$ ), with the YFP, CFP and FRET filter sets (Omega Optical Inc.), under identical conditions and processed with Scion Image software version beta 4.0.2 (Scion Corp.). The images were aligned by pixel shifting, inverted, and background was subtracted. Images from the YFP and CFP filter sets were multiplied with their previously assessed correction factors ( 0.19 for YFP and 0.59 for CFP) and subtracted from the FRET filter set picture. The remaining signal was multiplied by 3 for better visualization and represents the corrected FRET. Representative pictures are shown. 10 out of 10 analysed cells showing similar expression of CFP and YFP fusion proteins also gave FRET signal.

\section{Cell staining and immunofluorescence analyses}

Cells were washed in PBS and fixed for 5 min in $3.7 \%(\mathrm{w} / \mathrm{v})$ paraformaldehyde in CSK buffer (10 mM PIPES, pH 6.8, $10 \mathrm{mM} \mathrm{NaCl}, 300 \mathrm{mM}$ sucrose, $3 \mathrm{mM} \mathrm{MgCl}$, $2 \mathrm{mM}$ EDTA) at room temperature. Permeabilization was performed with $1 \%$ Triton X-100 in PBS for 15 min at room temperature. Cells were incubated with primary antibodies diluted in PBS with $1 \%$ goat serum for to $1 \mathrm{~h}$, washed 3 times for $10 \mathrm{~min}$ with PBS, incubated for $1 \mathrm{~h}$ with the appropriate secondary antibodies diluted in PBS with 1\% goat serum, and washed 3 times for 10 min with PBS. Antibodies used were rabbit anti- SNEV ${ }^{\text {Prp19/hPso4 }}$ antibody Prp19-867, and anti Sec6 (Calbiochem). As secondary antibodies, TRITC labelled anti-rabbit or anti-mouse antibodies (Jackson Immunoresearch Laboratories) were used. Microscopy and image analysis was carried out using a Zeiss DeltaVision Restoration microscope as described previously [5, 7, 26].

\section{Preparation of spliceosomal complexes}

Human spliceosomal complexes were prepared as described [7, 27]. Briefly, a mixture of spliceosomal complexes was assembled on biotinylated, radioactively labeled RNA. As splicing substrate, adenovirus (AD1) transcript, was used. The substrate was biotin-labeled and incubated under splicing conditions with HeLa nuclear extracts in $1 \mathrm{ml}$ reactions at $30^{\circ} \mathrm{C}$ for $1 \mathrm{~h}$, forming both active spliceosomes and assembly intermediates. After incubation the samples were immediately loaded onto a $2.5 \times 75-\mathrm{cm} \mathrm{S-500} \mathrm{gel} \mathrm{filtration} \mathrm{column,} \mathrm{and} \mathrm{pooled}$ fractions from the spliceosome peak were affinity-selected on streptavidin beads [28]. Proteins bound to the beads were washed three times in wash buffer $(100 \mathrm{mM} \mathrm{NaCl}, 20 \mathrm{mM}$ Tris- $\mathrm{HCl}$ $\mathrm{pH}$ 7.5), then eluted in $0.3 \mathrm{~mL}$ of elution buffer (2\% SDS, $20 \mathrm{mM}$ Tris- $\mathrm{HCl} \mathrm{pH} 7.5,20 \mathrm{mM}$ DTT). Eluted proteins were precipitated with $1 \mathrm{~mL}$ of methanol together with $12 \mu \mathrm{g}$ of slipper limpet glycogen carrier and finally resuspended in $50 \mu \mathrm{L}$ of elution buffer. This procedure was repeated 12 times, and the resulting samples were pooled separately for each of the premRNA substrates. Based on the staining with Coomassie blue, we estimate that each fraction contained $\sim 6-10 \mu \mathrm{g}$ of protein in total. For the background control, nuclear extract was incubated without labelled RNA, followed by gel filtration as described above. Beads were mixed with the fractions that corresponded to the ones that contained labelled RNA in the 
above-described experiment. Beads were washed, and the bound material was eluted as above.

\section{In vitro splicing assay}

Nuclear extracts used in the splicing assays were obtained commercially from Dundee Cell Products Ltd. Splicing assays were done using uniformly labeled, capped pre-mRNAs incubated with nuclear extract as described previously [24]. 80,160 or 320 pMol of purified recombinant proteins were added to the splicing reactions. The adeno-pre-mRNA was transcribed from Sau3Al-digested plasmid pBSAd1 [29]. The splicing reactions were loaded on a $10 \%$ polyacrylamide, $8 \mathrm{M}$ urea denaturing gel and run in $1 \times$ TBE to separate the splicing products.

\section{Alternative splicing assays}

HeLa cells were transiently co-transfected in triplicates with pMT-E1A and $0.5,1$ or $2 \mu \mathrm{g}$ pEGFFP-C2 containing either full length Exo70, $\triangle C C$ or $C C$ or empty pEGFP-C1 by Metafectene Pro transfection reagent (Biontex). Total RNA was isolated $48 \mathrm{~h}$ post transfection and subjected to reverse transcribed using SuperScript ${ }^{\mathrm{TM}}$ III Reverse Transcription. To exclude the possibility that the RNA isolation was contaminated with pMT-E1A vector DNA, RNA was treated with DNase I (Ambion) prior to cDNA synthesis. E1A alternatively spliced isoforms were amplified from $3 \mu \mathrm{l}$ cDNA by PCR in $50 \mu \mathrm{l}$ reactions with the KAPA 2G Robust Polymerase (Peqlab) using primers E1A_Exon1_forward 5'-GTT TTC TCC TCC GAG CCG CTC CGA-3' and E1A_Exon2_reverse 5'-CTC AGG CTC AGG TTC AGA CAC AGG-3' at final concentrations of $500 \mathrm{nM}$. After 5 min of denaturation, 30 PCR-cycles $\left(30 \mathrm{~s} / 95^{\circ} \mathrm{C}, 30 \mathrm{~s} / 711^{\circ} \mathrm{C}\right.$ and $30 \mathrm{~s} / 72^{\circ} \mathrm{C}$ ) were performed. For the quantification of $\mathrm{E} 1 \mathrm{~A}$ isoforms generated by in vivo splicing, $1 \mu \mathrm{l}$ of each PCR product was subjected to Chip-based capillary electrophoresis with the Agilent 2100 Bioanalyzer and the proportional amount of each fragment to the whole yield of splicing products was calculated.

For the detection of Exo70 alternatively spliced isoforms, cDNA was prepared as described above. In this case, primers Exo70_SpliceVar for 5'-CCC CAA CAA GAG GAA AGA CA-3' and Exo70_SpliceVar_rev 5'-TTG ACG AAG GCA CTG ACG-3' for amplification of Exo70 in different cell lines, and primer Exo70_SpliceVar_for was used together with the reverse primer 3 5'- TGC TTG TCG TTC AAG GCC-3' when using cDNA from Exo70 overexpressing cells as template. All other steps were carried out as described above.

One-way ANOVA F-tests were performed using R version 2.9.1 for comparing levels of splice isoforms. 


\section{RESULTS}

Identification of proteins interacting with the SNEV Prp19/Pso4/CDC5L associated complex In a recent Yeast Two-Hybrid screening using SNEV ${ }^{\text {Prp19/Ps04 }}$ as bait, we found Exo70 as prey [7]. In addition, recently co-precipitations of the core complex, using antibodies against CDC5L, a member of the core complex and SKIP, which is described as associated with the core complex [4], have been performed [16]. Thereby, a large number of proteins involved in a variety of cellular functions were identified, including factors involved in cell cycle regulation, DNA repair, trafficking, the ubiquitin/proteasome system, chaperones, chromatin remo deling, aging and the cytsoskeleton besides factors involved in pre-mRNA splicing and transcription [16]. Interestingly, 4 out of 8 members of the exocyst complex were identified. Since the nuclear localization of the exocyst has not yet been reported, we decided to analyze in more

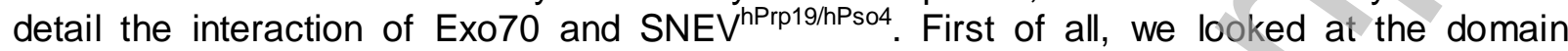
structure and putative nuclear localization signals of Exo70 (Fig. 1A). The protein consists of 19 a-helices connected by loops of varying length and can be subdivided into an aminoterminal $(\mathrm{N})$ domain, a middle $(\mathrm{M})$ domain and a carboxyl-terminal (C) domain [30]. Several regions with polar compositional bias (especially 160-180, 240-320, 500-550) might represent a flexible hinge. Directed yeast two-hybrid tests were performed to exclude autoactivation and to confirm the library screening result (Fig. 1B). In order to narrow down the interaction domain, several truncated forms of SNEV as well as of Exo70 were cloned into the yeast twohybrid vectors. First we tested several truncation mutants of SNEV against full length Exo70 (Fig. 1C). Colony formation of yeast transformants was observed only with SNEV constructs containing the amino acids 68-90. From our recent findings, the amino acids between 68 and 90 are also involved in SNEV ${ }^{\text {hPrp19/hPso4 }}$ homo-oligomerization [5] as well as for binding the alternative splicing factor Blom7 $\alpha$, a novel splicing factor interacting with SNEV ${ }^{\mathrm{hPrp} 19 / \mathrm{hPs} 04}$ [7]. These data together suggest that either this domain is indeed an interaction "hot-spot", or that Exo70 does not interact with monomeric SNEV ${ }^{\mathrm{hPrp} 19 / \mathrm{hPs}^{2} 4}$ but associates with a structure that forms by SNEV ${ }^{\mathrm{hPrp} 19 / \mathrm{hPs} 04}$ oligomerization only. For the mapping of the interaction domain on Exo70 we used amino-terminal deletion mutants together with full length SNEV in a directed Yeast Two-Hybrid (Fig. 1D). Thereby, the CC domain was found to be necessary and sufficient for SNEV binding. In addition, we found that the exocyst subunit Sec6 and the chaperone TCP1 were also present in the immunoprecipitates of SNEV ${ }^{\mathrm{hPrp} 19 / \mathrm{hPs} 04}$, SKIP and Blom7a, further confirming these protein associations (Fig. S1 and S2).

\section{The interaction between SNEV ${ }^{\mathrm{hPrp19} / \mathrm{hP} \text { s04 }}$ and Exo70 is direct}

In order to confirm the interaction between SNEV ${ }^{\text {hPrp19/hPso4 }}$ and hExo70, we performed pulldown experiments. Myc-SNEV ${ }^{\text {hPrip19/hPso4 }}$ was co-precipitated by $\mathrm{His}_{6}$-Exo70 bound to $\mathrm{Ni}^{2+}-\mathrm{NTA}^{-}$

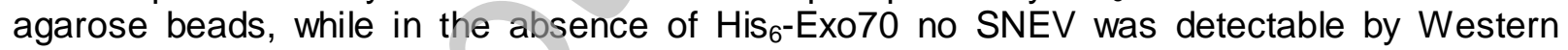
blotting (Fig. 2A). Furthermore, we pulled down full length $\mathrm{His}_{6}$-Exo70 as well as $\mathrm{His}_{6}$-CC, but

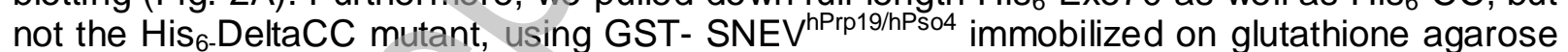
beads (Fig. 2B). Thus, we conclude that the interaction between SNEV ${ }^{\text {hPrp19/hPso4 }}$ and ExO70 is direct and mediated by the CC domain of Exo70. Finally, we inserted the cDNAs of SNEV ${ }^{\mathrm{hPrp} 19 / \mathrm{hPs} 04}$ and Ex070 into pECFP and pEYFP vectors and performed MicroFRET analysis [25] in COS-1 cells. A clear FRET signal was detected throughout the cells, while SNEV lacking the amino-terminal 89 amino acids that comprise the putative Exo70 interacting domain did not yield a detectable FRET signal (Fig. 2C). Negative controls using cotransfection with either SNEVhPrp19/hPso4 or Exo70 fusion constructs with the corresponding empty vector did not result in detectable FRET signals (data not shown). Although these results further confirm the interaction between SNEV ${ }^{\text {hrpr19/hPso4 }}$ and Exo70, their significance in terms of localizing the interaction within the cell is limited. The cellular localization of endogenous SNEV ${ }^{\text {Prp19/hPso4 }}$ is usually nuclear and was probably altered either by overexpression or by the interaction with free EYFP-Exo70 that might interfere with the import of SNEV into the nucleus.

Exo70 shuttles to the nucleus in HeLa cells and colocalizes with SNEVhPrp19/hPso4 Although the predicted localization for Exo70 by PSORT2 [31] is nuclear, it has not been 
observed as a nuclear protein yet. A reason for this might be the presence of a putative Crm1 dependent leucine-rich nuclear export signal predicted by the NetNES 1.1 [32]. Therefore, we tested if the localization of Exo70-EGFP changes within HeLa cells after blocking nuclear export by incubation with Leptomycin $B(L M B)$, a reagent that alkylates and inhibits CRM1/Exportin1, a protein required for nuclear export of proteins containing a nuclear export sequence [33]. $2 \mathrm{~h}$ after transfection with pExo70-EGFP, cells were incubated with LMB for 8 $\mathrm{h}$ and then fixed for immunostaining. Indeed, Exo70-EGFP accumulates in the nucleus upon

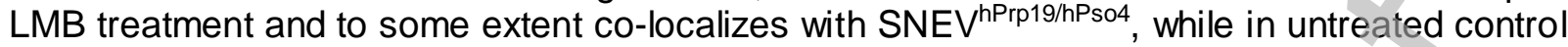
cells it was predominantly located in the cytoplasm and at the membranes (Fig. $3 \mathrm{~A}$, upper panel). However, there are specific regions of the nucleus where there is only SNEV ${ }^{h P r p 19 / h P s o 4}$ or EGFP-Exo70, which might indicate additional functions of both proteins that are not dependent on their interaction or might be caused by overexpression of EGFP-Exo70 and LMB treatment. Using our monoclonal antibody against endogenous Exo70, the nuclear accumulation of Exo70 upon LMB treatment was confirmed (Fig. 3B). Finally, we overexpressed Exo70, $\triangle \mathrm{CC}$ and $\mathrm{CC}$ and detected them using monoclonal anti-Exo70 antibodies. Without LMB treatment, CC and Exo70 are detectable in nuclei (Fig. 3C), while upon LMB treatment all are colocalizing with SNEV in the nucleus (Fig. 3D). Surprisingly, another subunit of the exocyst, Sec6 (EXOC3) also localizes to the nucleus upon blocking nuclear export (see supplementary figures S3). These results suggest that at least 2 members of the exocyst indeed shuttle between cytoplasm and nucleus. Together with the results of the large-scale IP, the possibility is raised that the whole exocyst shuttles, although the function of this movement remains unclear. In order to confirm that endogenous Exo70 is present in the nucleus we probed nuclear extract, cytoplasmic extract S100 from HeLa cells and purified mature spliceosomes for the presence of Exo70. Indeed we were able to detect Exo70 in all cellular fractions tested (Fig. 4). Especially its presence together with SNEV in the mature spliceosome suggested that this interaction might play a role in pre-mRNA splicing.

\section{The coiled coil domain of Exo70 inhibits mRNA splicing in vitro}

In order to test if the interaction between Exo70 and SNEVhPrp19/hPso4 is important for premRNA splicing, we added the recombinantly expressed proteins Exo70, CC and $\triangle \mathrm{CC}$ to in vitro splicing assays. Indeed, the splicing reaction was inhibited by addition of increasing amounts of CC by $44 \%$, compared to the control splicing reaction (Fig. 5). These results indicate that the interaction of Exo70 with SNEV ${ }^{\text {hPrp19/hPso4 }}$ might be involved in pre-mRNA splicing in vitro. However, these results could also be explained by non-specific titration effect. To further test if Exo70 is indeed involved in pre-mRNA splicing, we examined a possible function of Exo70 and its deletion mutants on splicing in vivo.

\section{Exo70 and its deletion mutants infiuence mRNA splicing in vivo}

Since the coiled coil domain of Exo70 turned out to influence mRNA splicing in vitro, we investigated the impact of Exo70 on splicing of a model substrate in vivo. Therefore, we used an in vivo splicing assay based on the alternative splicing of the adenovirus E1A gene. Alternative splicing of E1A gives rise to five isoforms (9S, 10S, 11S, 12S, 13S) [34] (Fig. 6A). We co-transfected HeLa cells with the E1A minigene together with increasing amounts of EGFP-Exo70 or its deletion mutants $\triangle \mathrm{CC}$ and CC or empty vector. As negative control we used empty pEGFP. E1A isoforms were detected by semi-quantitative PCR. Exo70 as well as the two deletion mutants significantly alter the E1A splicing pattern when compared to EGFP control (Fig. 6C). PCR products were quantitated by microfluidics-based capillary gel electrophoresis using the Bioanalyzer (Agilent), where molar ratios were calculated from 3 independent experiments and in turn converted into percental fractions of total $\mathrm{E} 1 \mathrm{~A}$ isoforms (Fig. 6D). While we see a significant dose dependent change using Exo70 full length, a small change was also seen using the truncated isoforms which does not seem dose dependent. For example, the $13 \mathrm{~S}$ isoforms goes down to $32 \%$ of all isoforms in the highest dose of Exo70 overexpression, compared to $40.5 \%$ in the corresponding negative control. In order to control for correct size and comparable expression levels of Exo70 and its mutants, cell lysates were analyzed by Western Blotting with anti-GFP antibody (Fig. 6B). 
Alternative splicing of Exo70 is cell type-dependent and changes during cellular aging. During our attempts of amplifying the cDNA coding for Exo70, we discovered at least 4 alternatively spliced Exo70 isoforms in HeLa. Sequence analysis and databank mining showed that only two of them were known isoforms, while two were novel. These sequence data have been termed Exo70 5 and Exo70 6 and submitted to the GenBank database under accession No. FJ457119 and FJ457120. Fig. 7A gives an overview over the exon-intron structure of all known Exo70 isoforms, including the two novel isoforms Exo70 isoform 5 and Exo70 isoform 6. Interestingly, while the secondary structure of the Exo70 protein consist of a series of alpha helices, the region varying between isoforms is predicted to be largely unstructured [30] and thus the isoforms might differ by the flexibility of the domains. Since several alternative splicing factors change their own splicing pattern, we tested if Exo70 influences alternative splicing of its own mRNA. Therefore we overexpressed Exo70 and its deletion mutants $\triangle C C$ and $C C$ in HeLa cells and quantified the differentially spliced Exo70 isoforms (Fig. 7B). To avoid the predominant amplification of mRNA transcribed from the vector, which corresponds to isoform 1 , we designed an alternative reverse primer that binds to a non-constitutive exon which is spliced out in isoform 1. Here, the proportion between isoform 5 and isoform 6 is not changed by ASF/SF2, indicating that Exo70 mRNA might not be a target of ASF/SF2. The same holds true for Exo70 and $\triangle \mathrm{CC}$, while the coiled coil do main alone causes a small, but significant shift in such a way that levels of isoforms 5 and 6 are no longer significantly different. In order to find out if our newly identified isoforms are specific for HeLa cells, we designed primers that bind upstream and downstream of the variable region. In a variety of different cell strains and conditions, we did not detect isoform 4, while isoform 3 shows very low to low abundance in HeLa cells, young and senescent fibroblast from two different donors, and three independent RNA isolations from confluent and subconfluent MDCK (Madine darby canine kidney) cells (Fig. $7 \mathrm{C}$ ). The high consistence among the results derived from HeLa cells, fibroblasts or MDCK cells indicates that our assay is reliable and reproducible. Since Exo70 was first characterized in MDCK cells, where the exocyst complex, targeted by Exo70, is recruited from the cytosol to cell-cell contacts [35], [36], we wondered if the confluence state of these cells might be associated with a shift in the distribution of Exo70 isoforms, but this does not seem to be the case (see Fig. 7C). However, it is remarkable that the splicing pattern does not significantly change during 5 months of continuous culture between the time points of RNA isolation. Fig. 7D shows the distribution of Exo70 isoforms in HUVEC (Human umbilical vein endothelial cells) lines derived from three different donors. Here, the situation is different: There is high variability between the different donors, and within the donors, the splicing pattern clearly changes when the cells have reached senescence. This is also true for RPTECs (Renal proximal tubular epithelial cells) (Fig. 7E), indicating a so far unknown donor-dependent variation in alternative splicing. 


\section{DISCUSSION}

The exocyst is an evolutionarily conserved octameric protein complex that directs post-Golgi vesicles to specific localizations at the plasma membrane prior to vesicle fusion. It consists of subunits Sec3, Sec5, Sec6, Sec8, Sec10, Sec15, Exo70, and Exo84, also termed EXOC1, EXOC2, EXOC3, EXOC4, EXOC5, EXOC6, EXOC7, and EXOC8. The function of the exocyst complex is essential for many cellular processes, reviewed in [37]. Of major importance for exocyst function is also the subunit Exo70 which is critical for assembly of the complex and its recruitment to the plasma membrane upon insulin signalling [38]. Besides, Exo70 plays a key role in cytoskeleton coordination by interacting with the Arp2/3 complex, a master regulator of actin polymerization [39]. The tight link between the cytoskeleton and Exo70 might also be reflected by our co-precipitation of a large number of cytoskeletal proteins [16].

Although so far no nuclear localization has been reported for human Ex070, at least some of the 23 Exo70 proteins known in $A$. thaliana are present in the nucleus [40]. Several additional indications support our finding that it shuttles to the nucleus. First of all, putative nuclear localization and crm1 dependent export signals are present in Exo70 [41] and indeed Exo70 accumulated in the nuclei upon blocking crm1 mediated export by LMB. Furthermore, an interaction with Nup62, which localizes to the central channel of the nuclear pore complex and occasionally binds cargo directly to support nuclear import, has been observed, although the authors report no nuclear localization of Exo70. Finally, one other subunit of the exocyst, Ex084 (EXOC8), has been found as interaction partner of the splicing factor Snp1, the yeast homologue of the $70 \mathrm{~K}$ protein [42]. While Exo84 directly binds to Exo70 in yeast, Snp1 is considered to be close to the SNEVhPrp19/hPso4 orthologue Prp19, since both are interaction partners of Prp8 and Smx3 [43], [44]. The interaction of Exo84 and Snp1 has been shown to be important in splicing, since a temperature sensitive mutant of Ex084 shows decreased splicing activity [42]. An independent Yeast Two-Hybrid screening identified Exo84 as Prp8 binding partner [45]. The authors assume that Ex084 might mediate interactions of Prp8 and the U1 snRNP and hypothesize that even though Ex084 is primarily located to the cytoplasm, a small fraction might localize to the nucleus and function in splicing.

In addition to the nuclear localization, endogenous Exo70 seems to accumulate in the granular compartment of the nucleoli upon inhibition of nuclear export (see Fig. 3C). This agrees with its involvement in splicing, since the nucleolar proteome is known to contain many splicing factors [46], and hypophosphorylated SR proteins localize around active NORs during telophase [47]. Together with its presence in affinity purified spliceosomes, this encouraged us to test if Exo70 might be involved in human pre-mRNA splicing. Indeed, the purified CC domain of Exo70 resulted in a decrease of splicing intermediates and spliced products, while $\triangle \mathrm{CC}$ or full length Exo70 did not. The $\mathrm{CC}$ domain may thus represent a dominant negative mutant. While clearly confirming the SNEV ${ }^{\mathrm{hPrp} 19 / \mathrm{hPs} 04}$-Exo70 interaction and demonstrating its importance, we cannot exclude the possibility that $\mathrm{CC}$ inhibits splicing by merely titrating away SNEV ${ }^{\mathrm{hPrp} 19 / \mathrm{hPs} 04}$ from its other interaction partners and thus inhibits splicing in vitro without any in vivo relevance.

Therefore, we used a minigene as splicing reporter construct and indeed found that overexpression of Exo70 significantly alters the splicing pattern in a dose-dependent manner and favours exon skipping of the E1A minigene, suggesting that Exo70 might be involved in alternative splice site selection.

Alternative splicing is a potent regulator of protein function: it specifies their binding properties, intracellular localization, enzymatic activity, protein stability and posttranslational modifications, whereupon effects range from very subtle attenuations to a complete abolishment of function or introduction of a new function [48]. Several splicing factors regulate splicing of their own mRNA [49],[50], Indeed, overexpression of Exo70 also influences the relative amounts of its own isoforms 5 and 6.

In addition, we observed different splice patterns depending on the cell lines used and their replicative age. Age related alternative splicing of some mRNAs is already known (reviewed in [51]), specifically also in senescent endothelial cells [52], although only very few data on the mechanistic basis is available. 
Furthermore, we identified also two previously unknown isoforms of Exo70. These isoforms differ in a putatively unstructured region between $\alpha$-helices 6 and 7 [30], probably resulting in different flexibility and binding affinities of Exo70 or providing sites for posttranslational modifications.

Still the function of this interaction remains unclear. One intriguing possibility is that it provides a direct signaling link between membrane events and nuclear splicing, allowing for rapid changes in the pattern of alternatively spliced proteins. Especially insulin signaling might be such a membrane event, since Exo70 mediates extracellular exposure of GLUT4 protein upon insulin signaling, possibly by directing vesicles to the site of membrane fusion [53]. This is remarkable, since in plants another member of the CDC5L associated complex, PRL1, the Arabidopsis thaliana homologue of PLRG1, is reported to affect glucose response and uptake [54].

A further link between membrane and splicing factors is the spreading initiation center, a structure at the cell membrane that is formed during spreading and adherence of human fibroblasts and that contains numerous RNA binding proteins [55].

Besides this signalling function, a transport function is as plausible, as the cargo of exocyst might also be mRNA. In this regard it is of note, that the exocyst has been found at the translocon, colocalizing with the translation machinery of the endoplasmic reticulum in yeast [56], as well as in mammalian cells, where it might help to transport mRNAs whose proteins are destined for export to the ER membrane [57]. This scenario seems possible since mRNA transport is coupled to splicing [58], and our results show the presence of Exo70 at the spliceosome.

Another question of interest with regards to Exo70 shuttling is to determine which physiological signal induces this movement. One possible signal is cell confluence. While Exo70 is suggested to be cytoplasmic (although we think that there is nuclear localization in fig. 4l of Matern et al. 2001) in contact naive MDCK cells, it translocates to the plasma membrane upon cell-cell contact [36]. Thereby, it might act as a direct communicator of cell contact events to the splicing apparatus.

\section{ACKNOWLEDGEMENTS}

Many thanks to J.F. Caceres, S. Hatakeyama, R. H. Scheller for expression plasmids, S.C. Hsu for antibodies, Hannes Schmid for helpful advices with FRET analysis, Boris Ferko for immunization of rabbits and mice, Matthias Hackl for help with statistical analysis as well as to Gustav Ritter and Martina Wostry for excellent technical support.

\section{FUNDING}

This work was supported by the Austrian Science Fund [NRN grant S93]; Genome Research Autria GEN-AU [Project 820982 „Non-coding RNAs”]; and grants by the Herzfelder'sche Familienstiftung and CE.R.I.E.S. HD is a recipient of a DOC-fFORTE-fellowship of the Austrian Academy of Sciences. 


\section{REFERENCES}

1 Wahl, M., Will, C. and Lührmann, R. (2009) The spliceosome: design principles of a dynamic RNP machine. Cell 136, 701-718

2 Grote, M., Wolf, E., Will, C., Lemm, I., Agafonov, D., Schomburg, A., Fischle, W., Urlaub, H. and Lührmann, R. (2010) Molecular architecture of the human

Prp19/CDC5L complex. Mol Cell Biol 30, 2105-2119

3 Ajuh, P., Kuster, B., Panov, K., Zomerdijk, J. C., Mann, M. and Lamond, A. I. (2000) Functional analysis of the human CDC5L complex and identification of its components by mass spectrometry. Embo J 19, 6569-6581.

4 Makarova, O. V., Makarov, E. M., Urlaub, H., Will, C. L., Gentzel, M., Wilm, M. and Luhrmann, R. (2004) A subset of human 35S U5 proteins, including Prp19, function prior to catalytic step 1 of splicing. Embo J 23, 2381-2391. Epub 2004 Jun 2303. Grillari, J., Ajuh, P., Stadler, G., Löscher, M., Voglauer, R., Ernst, W., Chusainow, J., Eisenhaber, F., Pokar, M., Fortschegger, K., Grey, M., Lamond, A. and Katinger, H. (2005) SNEV is an evolutionarily conserved splicing factor whose oligomerization is necessary for spliceosome assembly. Nucleic Acids Res 33, 6868-6883

Fortschegger, K., Wagner, B., Voglauer, R., Katinger, H., Sibilia, M. and Grillari, J. (2007) Early embryonic lethality of mice lacking the essential protein SNEV. Mol Cell Biol 27, 3123-3130

7 Grillari, J., Löscher, M., Denegri, M., Lee, K., Fortschegger, K., Eisenhaber, F., Ajuh, P., Lamond, A., Katinger, H. and Grillari-Voglauer, R. (2009) Blom7alpha is a novel heterogeneous nuclear ribonucleoprotein $\mathrm{K}$ homology domain protein involved in premRNA splicing that interacts with SNEVPrp19-Pso4. J Biol Chem 284, 29193-29204 Zhang, N., Kaur, R., Lu, X., Shen, X., Li, L. and Legerski, R. (2005) The Pso4 mRNA splicing and DNA repair complex interacts with WRN for processing of DNA interstrand cross-links. J Biol Chem 280, 40559-40567

9 Beck, B., Park, S., Lee, Y., Roman, Y., Hromas, R. and Lee, S. (2008) Human Pso4 is a metnase (SETMAR)-binding partner that regulates metnase function in DNA repair. J Biol Chem 283, 9023-9030

10 Zhang, N., Kaur, R., Akhter, S. and Legerski, R. (2009) Cdc5L interacts with ATR and is required for the S-phase cell-cycle checkpoint. EMBO Rep 10, 1029-1035

11 Voglauer, R., Chang, M., Dampier, B., Wieser, M., Baumann, K., Sterovsky, T., Schreiber, M., Katinger, H. and Grillari, J. (2006) SNEV overexpression extends the life span of human endothelial cells. Exp Cell Res 312, 746-759

12 Hatakeyama, S., Yada, M., Matsumoto, M., Ishida, N. and Nakayama, K. I. (2001) UBox proteins as a new family of ubiquitin-protein ligases. J Biol Chem 276, 3311133120

13 Löscher, M., Fortschegger, K., Ritter, G., Wostry, M., Voglauer, R., Schmid, J. A., Watters, S., Rivett, A. J., Ajuh, P., Lamond, A. I., Katinger, H. and Grillari, J. (2005) The U-box E3 ligase SNEV interacts with the 7 subunit of the $20 \mathrm{~S}$ proteasome. Biochem J 388, 593-603

14 Sihn, C., Cho, S., Lee, J., Lee, T. and Kim, S. (2007) Mouse homologue of yeast Prp19 interacts with mouse SUG1, the regulatory subunit of $26 \mathrm{~S}$ proteasome. Biochem Biophys Res Commun 356, 175-180

15 Song, E., Werner, S., Neubauer, J., Stegmeier, F., Aspden, J., Rio, D., Harper, J., Elledge, S., Kirschner, M. and Rape, M. (2010) The Prp19 complex and the Usp4Sart3 deubiquitinating enzyme control reversible ubiquitination at the spliceosome. Genes Dev 24, 1434-1447

16 Llères, D., Denegri, M., Biggiogera, M., Ajuh, P. and Lamond, A. (2010) Direct interaction between hnRNP-M and CDC5L/PLRG1 proteins affects alternative splice site choice. EMBO Rep 11, 445-451

17 Enninga, J., Levay, A. and Fontoura, B. (2003) Sec13 shuttles between the nucleus and the cytoplasm and stably interacts with Nup96 at the nuclear pore complex. Mol Cell Biol 23, 7271-7284 
18 Gietz, D., St. Jean, A., Woods, R. A. and Schiestl, R. H. (1992) Improved method for high efficiency transformation of intact yeast cells. Nucleic Acids Res 20, 1425

19 Böhm, E., Grillari, J., Voglauer, R., Gross, S., Ernst, W., Ferko, B., Kunert, R., Katinger, $\mathrm{H}$. and Borth, N. (2005) Establishment of a strategy for the rapid generation of a monoclonal antibody against the human protein SNEV (hNMP200) by flowcytometric cell sorting. J Immunol Methods 307, 13-23

20 Wieser, M., Stadler, G., Jennings, P., Streubel, B., Pfaller, W., Ambros, P., Riedl, C., Katinger, H., Grillari, J. and Grillari-Voglauer, R. (2008) hTERT alone immortalizes epithelial cells of renal proximal tubules without changing their functional characteristics. Am J Physiol Renal Physiol 295, F1365-1375

21 Hayflick, L. and Moorhead, P. (1961) The serial cultivation of human diploid cell strains. Exp Cell Res 25, 585-621

22 Hayflick, L. (1965) The limited in vitro lifetime of human diploid cell strains. Exp Cell Res 37, 614-636

23 Chang, M., Grillari, J., Mayrhofer, C., Fortschegger, K., Allmaier, G., Marzban, G., Katinger, H. and Voglauer, R. (2005) Comparison of early passage, senescent and hTERT immortalized endothelial cells. Exp Cell Res 309, 121-136

24 Lamond, A. I., Konarska, M. M. and Sharp, P. A. (1987) A mutational analysis of spliceosome assembly: evidence for splice site collaboration during spliceosome formation. Genes Dev 1, 532-543.

25 Youvan, D. C., Silva, C. M., Bylina, E. J., Coleman, W. J., Dilworth, M. R. and Yang, M. M. (1997) Calibration of Fluorescence Resonance Energy Transfer in Microscopy Using Genetically Engineered GFP Derivatives on Nickel Chelating Beads. Biotech. et alia 3, 1-18

26 Platani, M., Goldberg, I., Swedlow, J. R. and Lamond, A. I. (2000) In vivo analysis of Cajal body movement, separation, and joining in live human cells. J Cell Biol 151, 1561-1574.

27 Rappsilber, J., Ryder, U., Lamond, A. and Mann, M. (2002) Large-scale proteomic analysis of the human spliceosome. Genome Res 12, 1231-1245

28 Calvio, C., Neubauer, G., Mann, M. and Lamond, A. (1995) Identification of hnRNP P2 as TLS/FUS using electrospray mass spectrometry. RNA 1, 724-733

29 Konarska, M. M. and Sharp, P. A. (1987) Interactions between small nuclear ribonucleoprotein particles in formation of spliceosomes. Cell 49, 763-774.

30 Moore, B. A., Robinson, H.H. and Xu, Z. (2007) The crystal structure of mouse Exo70 reveals unique features of the mammalian exocyst. $\mathrm{J}$ Mol Biol 371, 410-421

31 Nakai, K. and Horton, P. (1999) PSORT: a program for detecting sorting signals in proteins and predicting their subcellular localization. Trends Biochem Sci 24, 34-36

32 la Cour, T., Kiemer, L., Møigaard, A., Gupta, R., Skriver, K. and Brunak, S. (2004) Analysis and prediction of leucine-rich nuclear export signals. Protein Eng Des Sel $17,527-536$

33 Hamamoto, T., Seto, H. and Beppu, T. (1983) Leptomycins A and B, new antifungal antibiotics. II. Structure elucidation. J Antibiot (Tokyo) 36, 646-650

34 Cáceres, J., Stamm, S., Helfman, D. and Krainer, A. (1994) Regulation of alternative splicing in vivo by overexpression of antagonistic splicing factors. Science 265,1706 1709

35 Grindstaff, K., Yeaman, C., Anandasabapathy, N., Hsu, S., Rodriguez-Boulan, E., Scheller, R. and Nelson, W. (1998) Sec6/8 complex is recruited to cell-cell contacts and specifies transport vesicle delivery to the basal-lateral membrane in epithelial cells. Cell 93, 731-740

36 Matern, H. T., Yeaman, C., Nelson, W. J. and Scheller, R. H. (2001) The Sec6/8 complex in mammalian cells: characterization of mammalian Sec3, subunit interactions, and expression of subunits in polarized cells. Proc Natl Acad Sci U S A 98, 9648-9653

37 He, B. and Guo, W. (2009) The exocyst complex in polarized exocytosis. Curr Opin Cell Biol 21, 537-542 
38 Bao, Y., Lopez, J., James, D. and Hunziker, W. (2008) Snapin interacts with the Exo70 subunit of the exocyst and modulates GLUT4 trafficking. J Biol Chem 283, 324-331

39 Zuo, X., Zhang, J., Zhang, Y., Hsu, S., Zhou, D. and Guo, W. (2006) Exo70 interacts with the Arp2/3 complex and regulates cell migration. Nat Cell Biol 8, 1383-1388

40 Chong, Y., Gidda, S., Sanford, C., Parkinson, J., Mullen, R. and Goring, D. (2010) Characterization of the Arabidopsis thaliana exocyst complex gene families by phylogenetic, expression profiling, and subcellular localization studies. New Phytol 185, 401-419

41 Fornerod, M., Ohno, M., Yoshida, M. and Mattaj, I. W. (1997) CRM1 is an export receptor for leucine-rich nuclear export signals. Cell 90, 1051-1060

42 Awasthi, S., Palmer, R., Castro, M., Mobarak, C. D. and Ruby, S. W. (2001) New roles for the Snp1 and Exo84 proteins in yeast pre-mRNA splicing. J Biol Chem 276, 31004-31015.

43 Gavin, A., Bösche, M., Krause, R., Grandi, P., Marzioch, M., Bauer, A., Schultz, J., Rick, J., Michon, A., Cruciat, C., Remor, M., Höfert, C., Schelder, M., Brajenovic, M., Ruffner, H., Merino, A., Klein, K., Hudak, M., Dickson, D., Rudi, T., Gnau, V., Bauch, A., Bastuck, S., Huhse, B., Leutwein, C., Heurtier, M., Copley, R., Edelmann, A., Querfurth, E., Rybin, V., Drewes, G., Raida, M., Bouwmeester, T., Bork, P., Seraphin, B., Kuster, B., Neubauer, G. and Superti-Furga, G. (2002) Functional organization of the yeast proteome by systematic analysis of protein complexes. Nature 415, 141 147

44 Ho, Y., Gruhler, A., Heilbut, A., Bader, G., Moore, L., Adams, S., Millar, A., Taylor, P., Bennett, K., Boutilier, K., Yang, L., Wolting, C., Donaldson, I., Schandorff, S., Shewnarane, J., Vo, M., Taggart, J., Goudreault, M., Muskat, B., Alfarano, C., Dewar, D., Lin, Z., Michalickova, K., Willems, A., Sassi, H., Nielsen, P., Rasmussen, K., Andersen, J., Johansen, L., Hansen, L., Jespersen, H., Podtelejnikov, A., Nielsen, E., Crawford, J., Poulsen, V., Sørensen, B., Matthiesen, J., Hendrickson, R., Gleeson, F., Pawson, T., Moran, M., Durocher, D., Mann, M., Hogue, C., Figeys, D. and Tyers, M. (2002) Systematic identification of protein complexes in Saccharomyces cerevisiae by mass spectrometry. Nature 415, 180-183

45 Kuhn, A. and Brow, D. (2000) Suppressors of a cold-sensitive mutation in yeast U4 RNA define five domains in the splicing factor Prp8 that influence spliceosome activation. Genetics 155, 1667-1682

46 Boisvert, F., van Koningsbruggen, S., Navascués, J. and Lamond, A. (2007) The multifunctional nucleolus. Nat Rev Mol Cell Biol 8, 574-585

47 Bubulya, P. A., Prasanth, K. V., Deerinck, T. J., Gerlich, D., Beaudouin, J., Ellisman, M. H., Ellenberg, J and Spector, D. L. (2004) Hypophosphorylated SR splicing factors transiently localize around active nucleolar organizing regions in telophase daughter nuclei. J Cell Biol 167, 51-63

48 Stamm, S., Ben-Ari, S., Rafalska, I., Tang, Y., Zhang, Z., Toiber, D., Thanaraj, T. and Soreq, H. (2005) Function of alternative splicing. Gene 344, 1-20

49 Jumaa, H. and Nielsen, P. (1997) The splicing factor SRp20 modifies splicing of its own mRNA and ASF/SF2 antagonizes this regulation. EMBO J 16, 5077-5085

50 Malygin, A., Parakhnevitch, N., Ivanov, A., Eperon, I. and Karpova, G. (2007) Human ribosomal protein $\mathrm{S} 13$ regulates expression of its own gene at the splicing step by a feedback mechanism. Nucleic Acids Res 35, 6414-6423

51 Meshorer, E. and Soreq, H. (2002) Pre-mRNA splicing modulations in senescence. Aging Cell 1, 10-16

52 Blanco, F. J., Grande, M. T., Langa, C., Oujo, B., Velasco, S., Rodriguez-Barbero, A., Perez-Gomez, E., Quintanilla, M., López-Novoa, J. M. and Bernabeu, C. (2008) Sendoglin expression is induced in senescent endothelial cells and contributes to vascular pathology. Circ Res 103, 1383-1392

53 Inoue, M., Chang, L., Hwang, J., Chiang, S. H. and Saltiel, A. R. (2003) The exocyst complex is required for targeting of Glut4 to the plasma membrane by insulin. Nature 422, 629-633 
54 Nemeth, K., Salchert, K., Putnoky, P., Bhalerao, R., Koncz-Kalman, Z., StankovicStangeland, B., Bako, L., Mathur, J., Okresz, L., Stabel, S., Geigenberger, P., Stitt, M., Redei, G. P., Schell, J. and Koncz, C. (1998) Pleiotropic control of glucose and hormone responses by PRL1, a nuclear WD protein, in Arabidopsis. Genes Dev 12, 3059-3073

55 de Hoog, C., Foster, L. and Mann, M. (2004) RNA and RNA binding proteins participate in early stages of cell spreading through spreading initiation centers. Cell 117, 649-662

56 Toikkanen, J. H., Miller, K. J., Soderlund, H., Jantti, J. and Keranen, S. (2003) The beta subunit of the Sec61p endoplasmic reticulum translocon interacts with the exocyst complex in Saccharomyces cerevisiae. J Biol Chem 278, 20946-20953

57 Lipschutz, J. H., Lingappa, V. R. and Mostov, K. E. (2003) The exocyst affects protein synthesis by acting on the translocation machinery of the endoplasmic reticulum. $J$ Biol Chem 278, 20954-20960

58 Reed, R. (2003) Coupling transcription, splicing and mRNA export. Curr Opin Cell Biol 15, 326-331 


\section{FIGURE LEGENDS}

Figure 1. Yeast two-hybrid screening identifies Exo70 as a putative interaction partner of SNEV hPrp19/hPso4.

(A) Scheme representing the domain structure of Exo70. Each domain consists of a bundle of alpha helices. Exo70 contains a putative nuclear export signal. A coiled coil structure in the $\mathrm{N}$ domain provides a protein binding site. (B) SNEV ${ }^{\mathrm{hPrp} 19 / \mathrm{hPs} 04}$ was used as bait protein in a yeast two-hybrid cDNA library screening and identified Exo70 as a putative interaction partner. While neither SNEVhPrp19/hPs04 nor Exo70 co-transformed together with the respective second empty vector allowed colony formation on high stringency drop out medium, cotransformation of GAL4-BD-SNEV and GAL4-AD-Exo70 into yeast two-hybrid reporter strain $\mathrm{AH} 109$ resulted in colony formation. (C) Co-transformation of different truncated forms of SNEV ${ }^{\text {hPrp19/hPso4 }}$ together with Exo70 showed that yeast colony growth depends on the presence of the amino acids 68 to 90 (U-box, U-Box domain; BD, binding domain; LCR, low complexity region; CC, coiled coil domain; GL, globular domain; ++--++, charged region; WD40, 7× WD40 repeats). (D) Several truncated forms of Exo70 were tested against SNEV ${ }^{\text {PPrp } 19 / \mathrm{hPs}^{2} 4}$ in order to map the interaction site. The $100 \mathrm{~N}$-terminal amino acids of Exo70 are necessary and sufficient for the interaction. "+" and "-" indicate colony formation upon cotransformation with SNEV.

\section{Figure 2. Interaction of SNEV ${ }^{\mathrm{hPrp} 19 / \mathrm{hPs}} \mathrm{s}$ and Exo70 is direct.}

(A) The yeast two-hybrid screening results were confirmed by co-immunoprecipitation. While

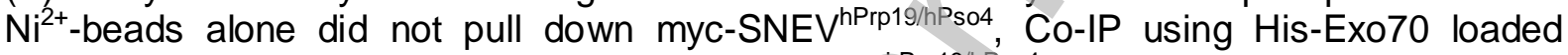
beads resulted in detectable amounts of myc-SNEVhPrp19/hPso4 on Western blots using anti-cmyc antibody. 50\% input was loaded. (B) GST- SNEV ${ }^{\text {hPro19/hPso4 }}$-in contrast to GST alonepulled down $\mathrm{His}_{6}$-tagged Exo70 as well as the $\mathrm{His}_{6}$-CC domain of Exo70, while $\Delta \mathrm{CC}$ was not pulled down by GST or GST-SNEV ${ }^{\text {hPrp19/hPso4 }} .25 \%$ input was loaded. (C) FRET analysis confirms SNEV-Exo70 interaction. COS-1 cells were co-transfected with ECFP-SNEV and EYFP-Exo70, and FRET analysis was performed as described, resulting in a detectable signal. Control FRET analysis using a SNEV deletion mutant lacking the $89 \mathrm{~N}$-terminal amino acids necessary for the interaction with Exo70 yielded no detectable signal.

Figure 3. Exo70 colocalizes with SNEV in the nucleus of HeLa cells upon inhibition of nuclear export.

(A) Exo70-EGFP (green) is located in the cytoplasm and at the plasma membrane of HeLa cells, while SNEV (red) is located in the nucleus. Upon inhibition of nuclear export by LMB, Exo70 accumulates within the nucleoplasm in a similar pattern as SNEV, sparing the nucleoli. (B) IF with antibody against endogenous Exo70 confirms accumulation of Exo70 in the nucleus upon inhibition of nuclear export. (C) Overexpression of His ${ }_{6}$-tagged Exo70 and two truncated forms ( $\triangle C C$ and $C C$, see Fig. 1C) and immunofluorescence staining using anti-Exo70 antibody. (D) IF with antibody against endogenous Exo70 confirms colocalization

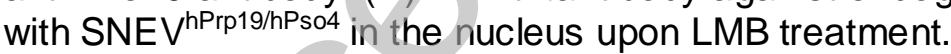

Figure 4. Exo 70 and SNEV are contained in the same complex in nuclear extracts.

Endogenous SNEVhPrp19/hPso4 and Exo70 are present in nuclear extract (NE), cytoplasmic S100 extract as well as in the mature spliceosome, while no signal is detected in the mock spliceosome purification. Our protocol for subcellular fractionation was established and tested for purity by Western Blotting using antibodies against nuclear (Lamin $A / C$ ) and cytoplasmic (GAPDH) marker proteins (lower panels). In a further experiment, fractions were prepared as described and tested for the presence of SNEV ${ }^{\mathrm{hPrp19} / \mathrm{hPs} 04}$ and Exo70 (upper panels).

\section{Figure 5. The coiled-coil domain of Exo70 inhibits splicing in vitro.}

(A) Recombinant Exo70, $\triangle \mathrm{CC}$, and $\mathrm{CC}$ were added in equimolar amounts to in vitro splicing reactions. Neither full length Exo70 nor the truncated form lacking the $100 \mathrm{~N}$-terminal amino acids influenced the efficiency of the splicing assay, while the CC deletion mutant inhibited 
the splicing reaction, resulting in a decrease of the lariat form. Symbols on the right-hand side of the gel represent (from top down): Lariat fused to Exon2, free lariat, pre-mRNA, spliced mRNA, Exon1. (B) Quantification of the ratio between lariat and pre-mRNA band intensities. Standard deviations are calculated from three independent experiments.

\section{Figure 6. Exo70 influences splicing in vivo.}

(A) Schematic representation of the alternative splicing pattern of the E1A minigene. Only major isoforms are depicted. Arrows denote binding sites for primers E1A Exon1 forward and E1A Exon2 reverse. (B) HeLa cells were co-transfected with pEGFP-C2-Exo70, $\triangle C C$ or CC. Empty pEGFP-C2 vector was used as negative control. Correct expression of transfected constructs was confirmed by resolving $50 \mu \mathrm{g}$ total protein extract on SDS-PAGE and probing with anti-GFP antibody. GFP, 29kDa; GFP-Exo70, $103 \mathrm{kDa}, \mathrm{GFP}-\triangle \mathrm{CC}, 90 \mathrm{kDa}$; GFP-CC, $42 \mathrm{kDa}$. (C) Overexpression of GFP-tagged full length and truncated forms of Exo70 influences E1A splicing in vivo. Total RNA was isolated $48 \mathrm{~h}$ post transfection, reverse transcribed and used as template in PCR reactions with E1A specific primers. $10 \mu \mathrm{l}$ of the PCR products were resolved on 1\% agarose gel. (D) Exo70 has a dose-dependent effect on splicing of E1A. Molar amounts of PCR products were calculated using the Agilent 100 Bioanalyzer and converted into percental fractions. Error bars represent the standard deviation of the average calculated across three individual experiments. Hela cells were transfected with different amounts of Exo70, its deletion mutants or empty vector. Asterisks indicate significant differences to the amount of the same product in the control transformed with an equivalent amount of GFP $\left({ }^{*} p<0.05 ;{ }^{* *} p<0.01\right.$ in one-way ANOVA F-test).

\section{Figure 7. Exo70 is itself present as multiple alternatively spliced isoforms.}

(A) Exon-intron organization of the Exo70 gene. Boxes denote exons. Exons are drawn to scale. Numbers below boxes indicate exon lengths (in bp). Numbers in between exons indicate intron lengths (in bp, not drawn to scale). In Exo70_4, the omission of the 5' splice site of the intron following Exon 6 leads to a longer alternative 6 a exon with a premature stop codon. Exo70_5 and Exo70_6 were not previously known in databases. (B) The CC deletion mutant of Exo70 influences splicing of Exo70 mRNA. To avoid detection of the predominant mRNA transcribed from the vector and allow only detection of endogenous Exo70 isoforms, we used a reverse primer binding to Exon 9, which is not present in the vector sequence which corresponds to Exo70 isoform 1. Overexpression of the CC deletion mutant significantly altered the relative abundances of Exo70 isoform 5 and isoform 6 as they are no longer significantly different in levels as they are in the other transfections. Asterisks ( $\left.{ }^{*}\right)$ indicate significant differences ( $p<0.05$ one-way ANOVA F-test). (C) Distribution of Exo70 isoforms is cell-type dependent. In HeLa and MDCK cells, the distribution of Exo70 isoforms is constant over several months in culture. In fibroblasts, the pattern is very similar across different donors. (D) In endothelial cells, distribution of Exo70 isoforms is donor-specific and probably dependent on aging. (E) The same is true for RPTECs. Y, young; S, senescent; C, confluent; SC, subconfluent. 
Biochemical Journal Immediate Publication. Published on 03 Jun 2011 as manuscript BJ20110183

Fig.1

\section{A Exo70 domain structure}

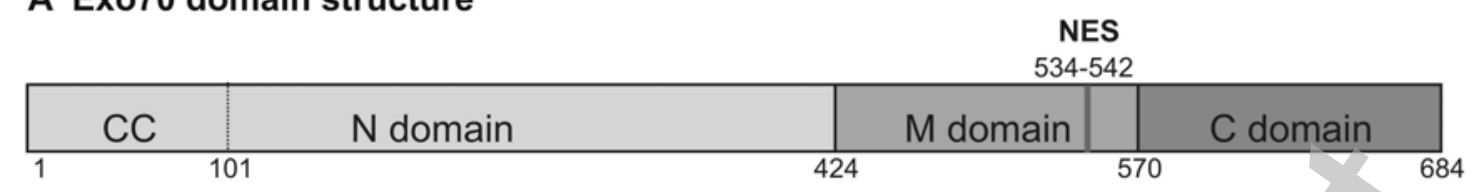

\section{B}
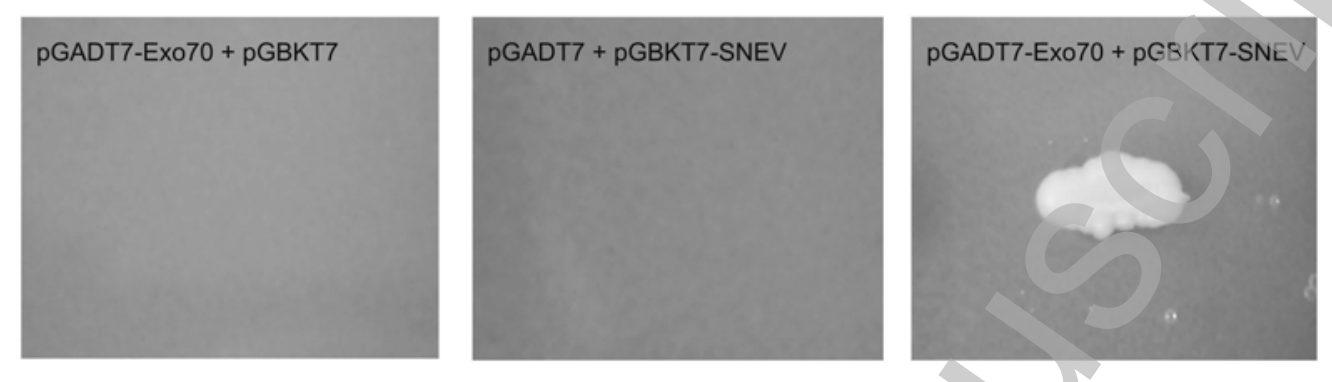

C

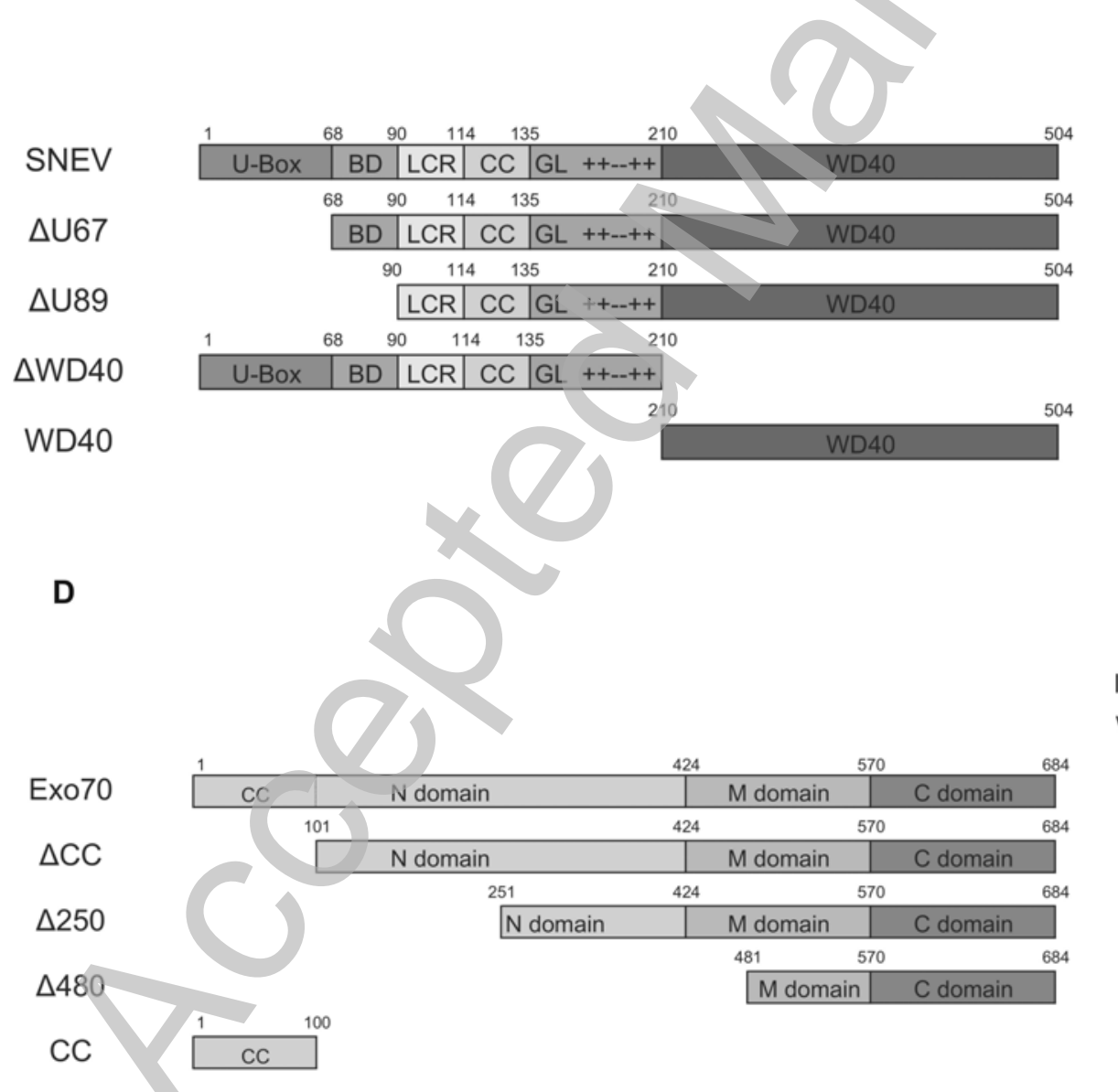

Interaction

with Exo70

Interaction

with SNEV

Licenced copy. Copying is not permitted, except with prior permission and as allowed by law.

(C) 2011 The Authors Journal compilation (c) 2011 Portland Press Limited 
Fig. 2

A

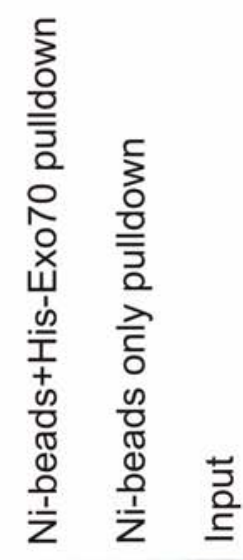

Anti-c-myc

B
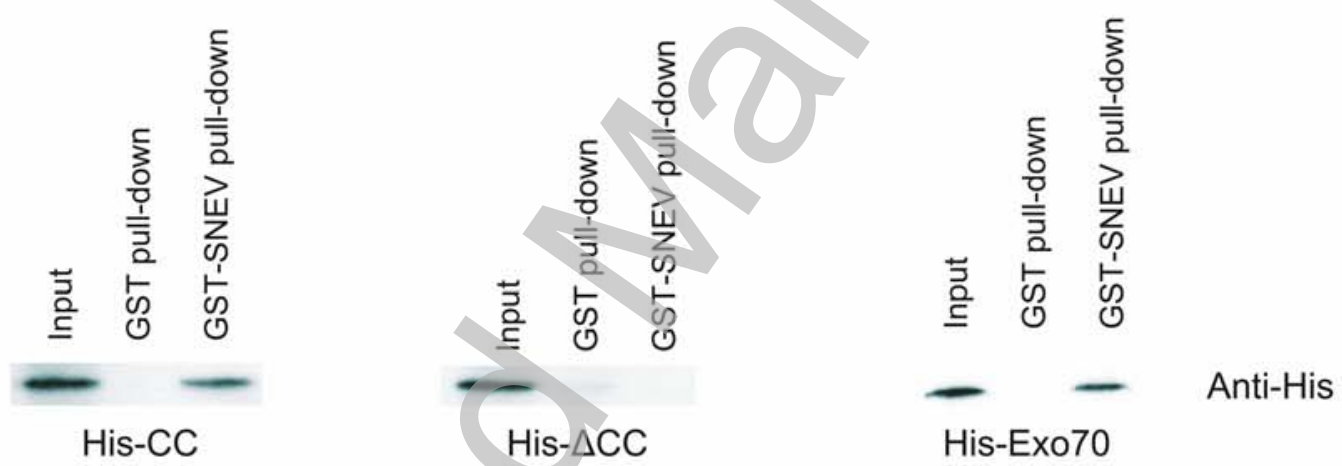

C
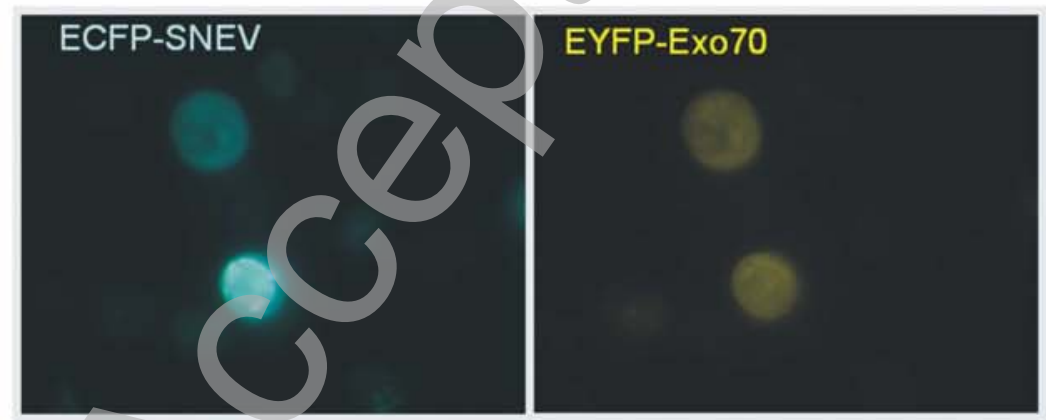

FRET

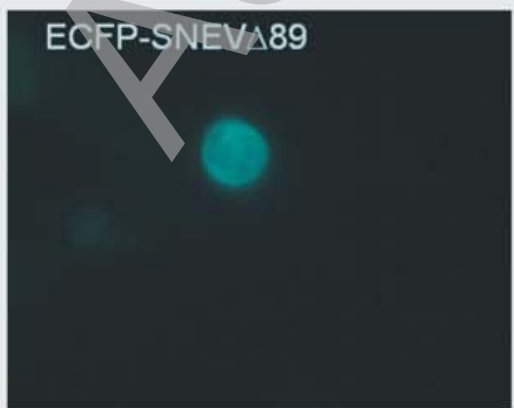

EYFP-Exo70

FRET

20

Licenced copy. Copying is not permitted, except with prior permission and as allowed by law. (C) 2011 The Authors Journal compilation (c) 2011 Portland Press Limited 
Fig. 3

A

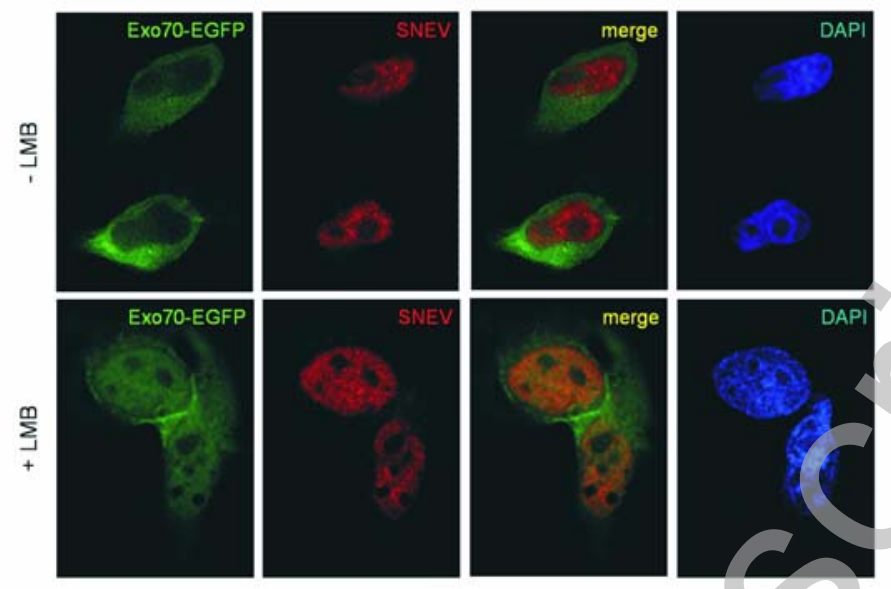

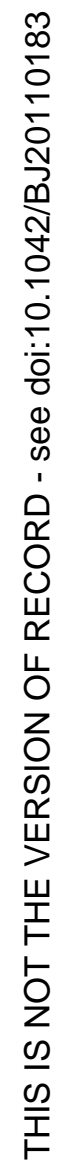

B

C

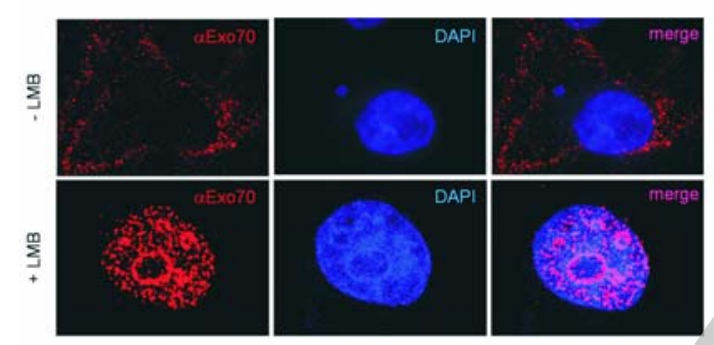

¿
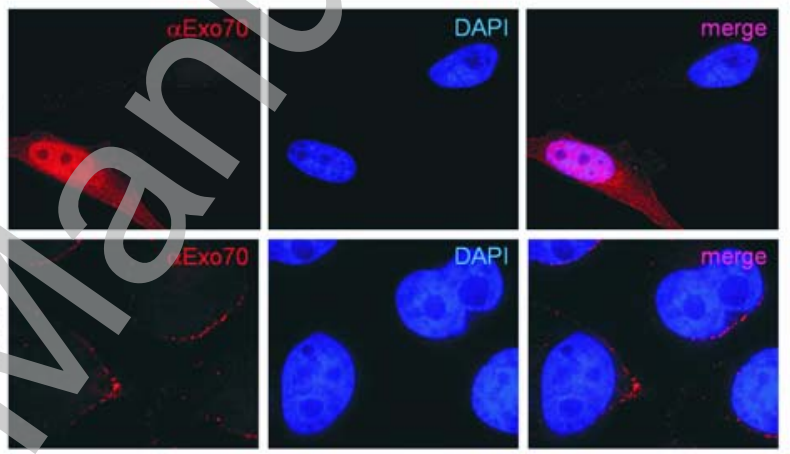

옹
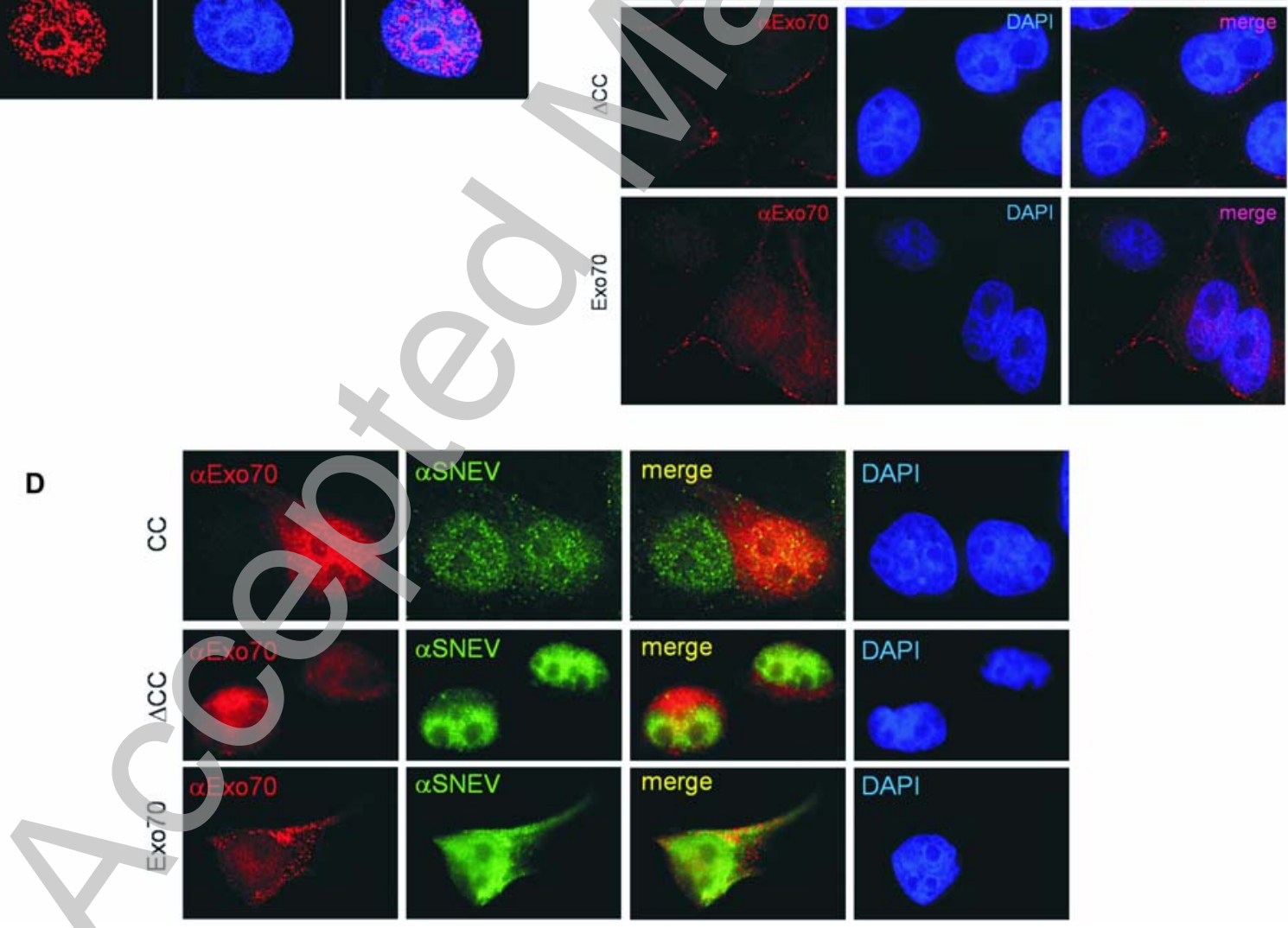

merge
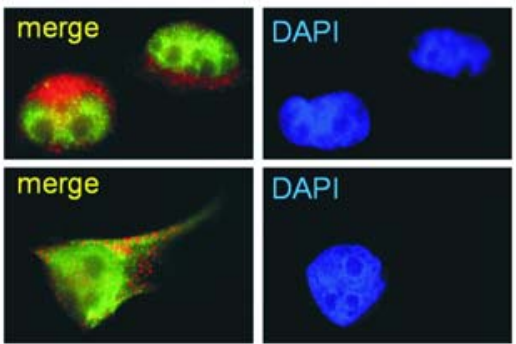
Fig. 4

A

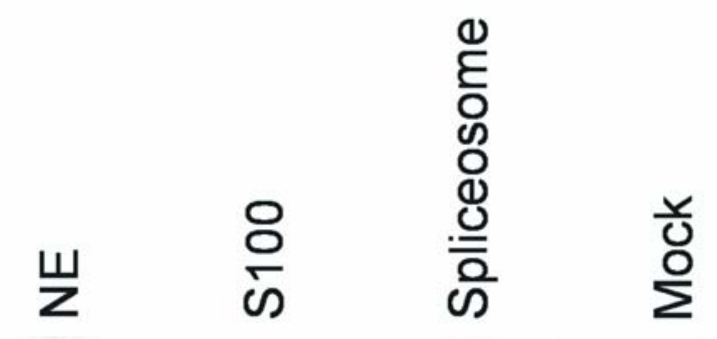

Anti-Exo70

Anti-SNEV

Anti-Lamin A/C

Anti-GAPDH 
Fig. $5 \quad \mathrm{~A}$
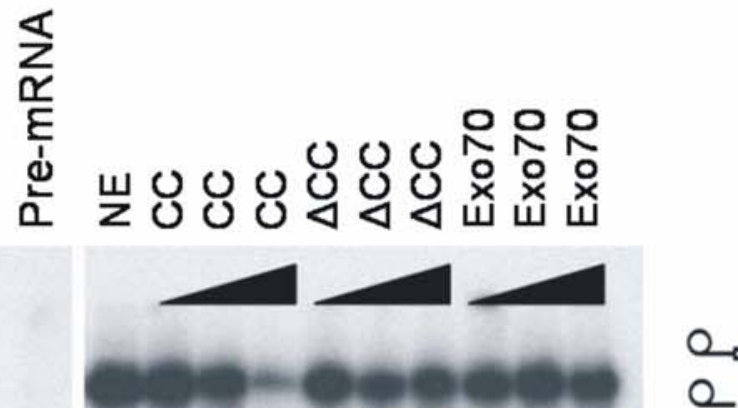

B

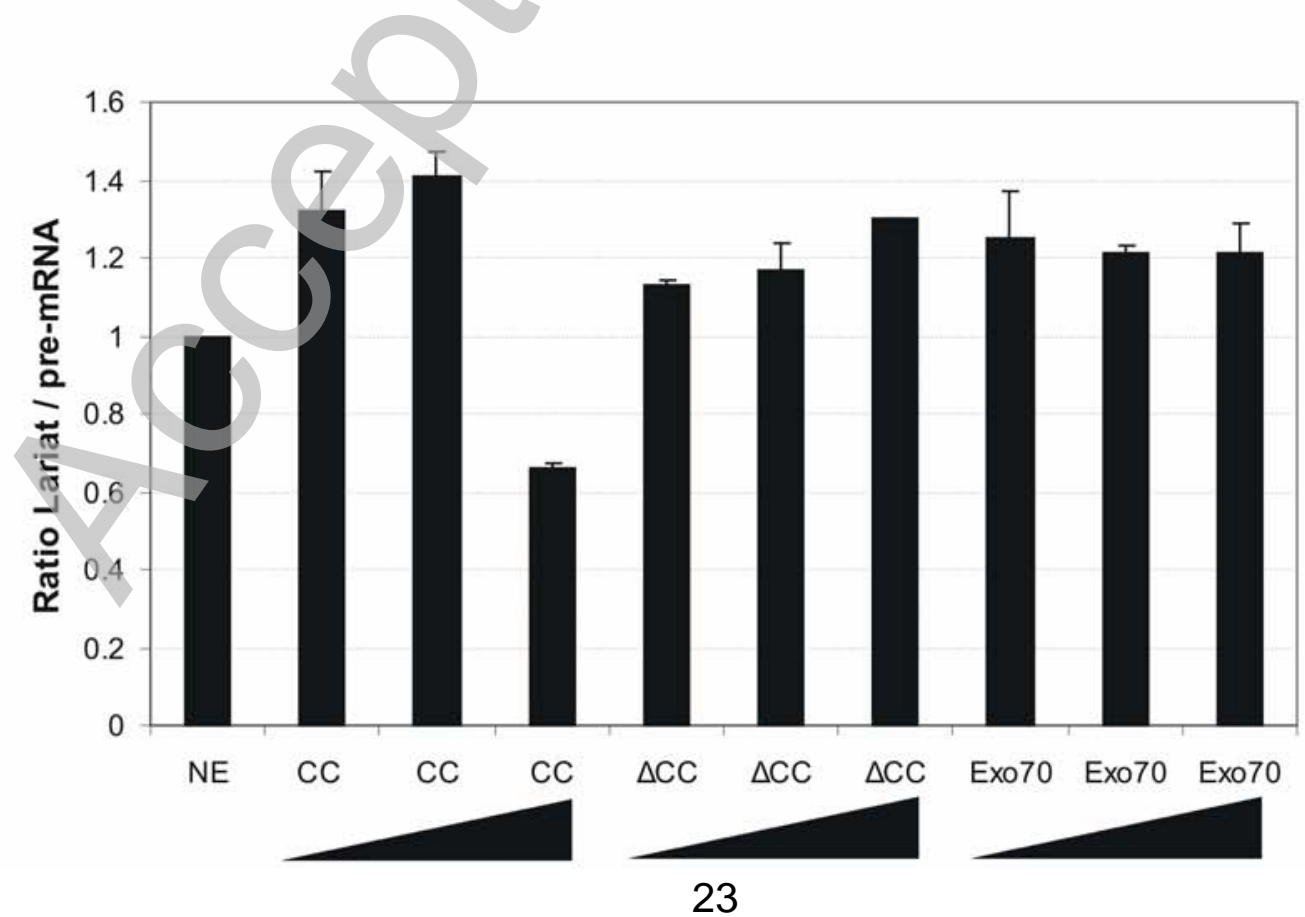

Licenced copy. Copying is not permitted, except with prior permission and as allowed by law. (C) 2011 The Authors Journal compilation (c) 2011 Portland Press Limited 
Fig. 6

A Alternative splicing pattern of E1A

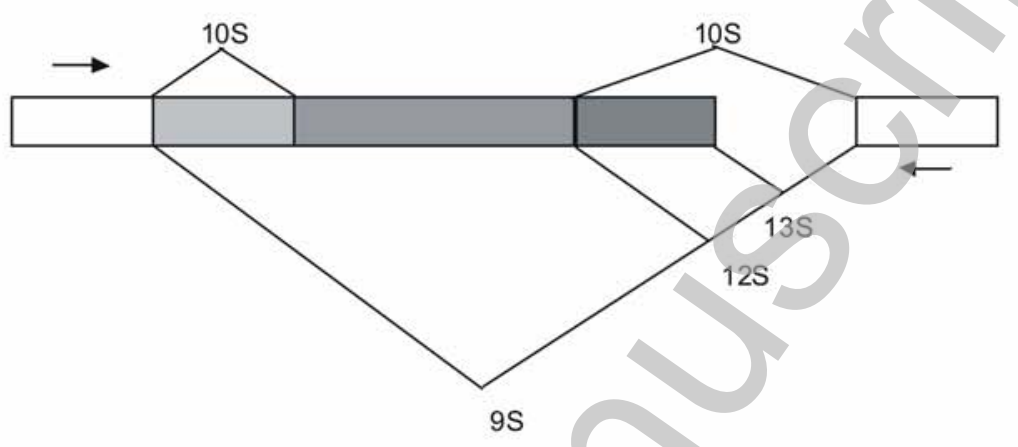

B

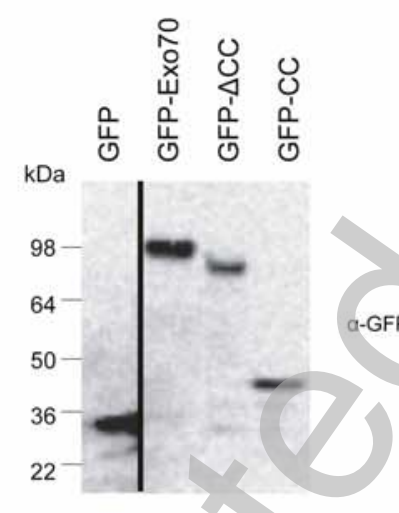

C

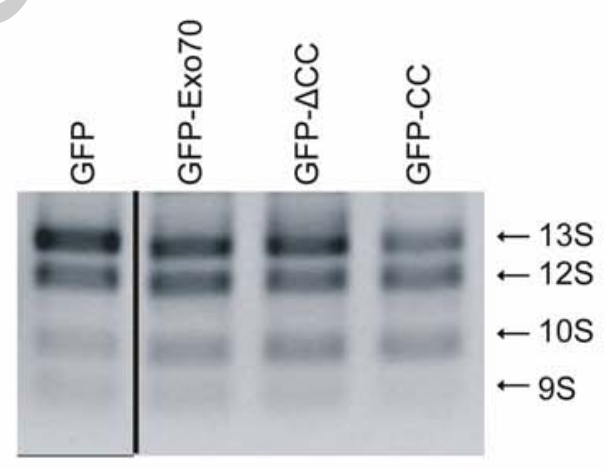

D

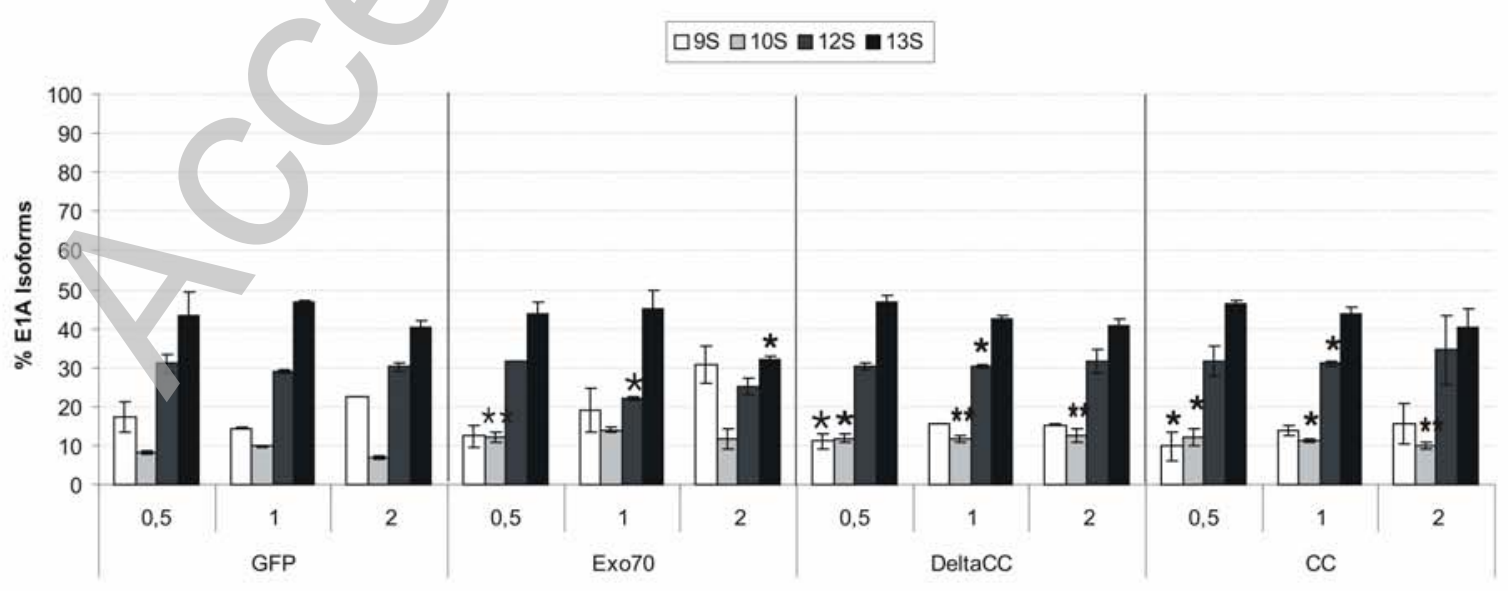

24

Licenced copy. Copying is not permitted, except with prior permission and as allowed by law. (C) 2011 The Authors Journal compilation (c) 2011 Portland Press Limited 
Fig. 7

A

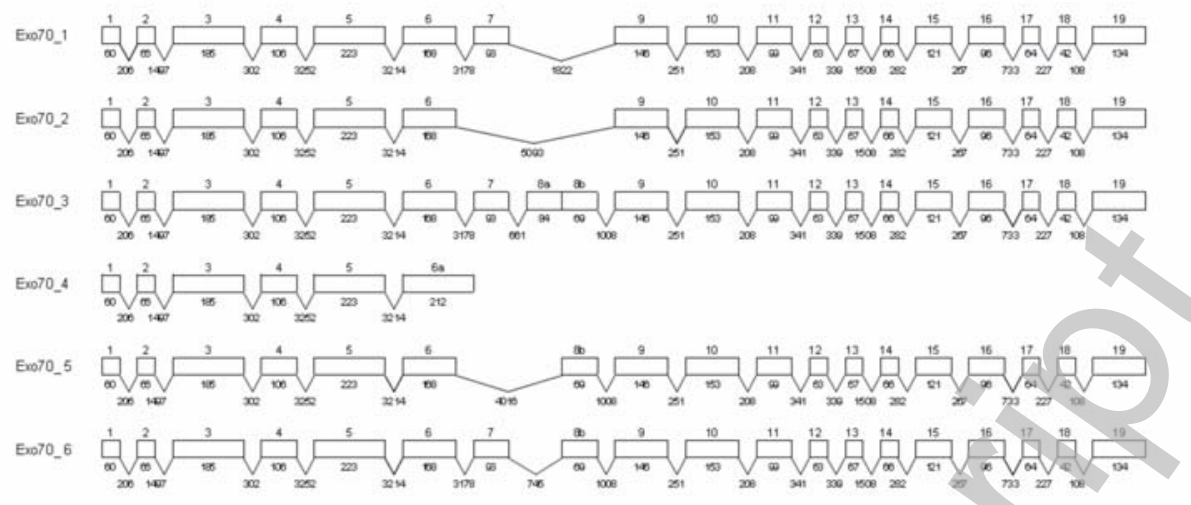

B

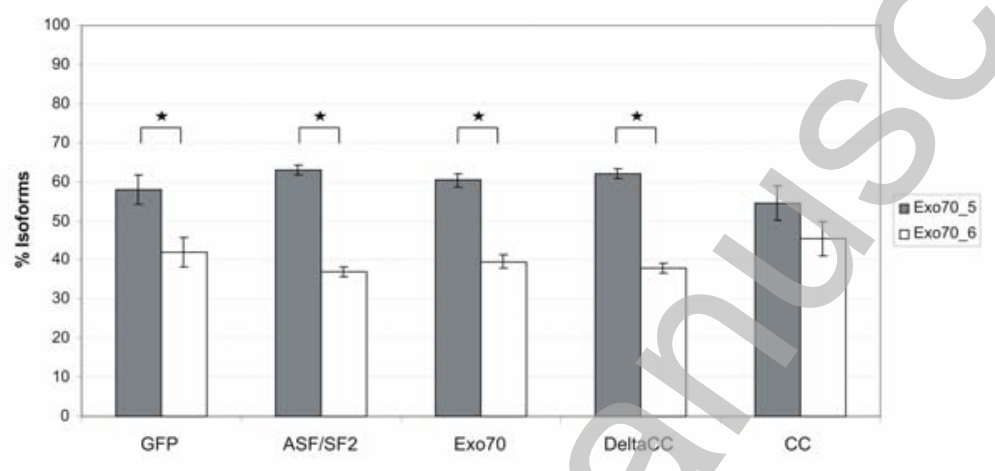

C

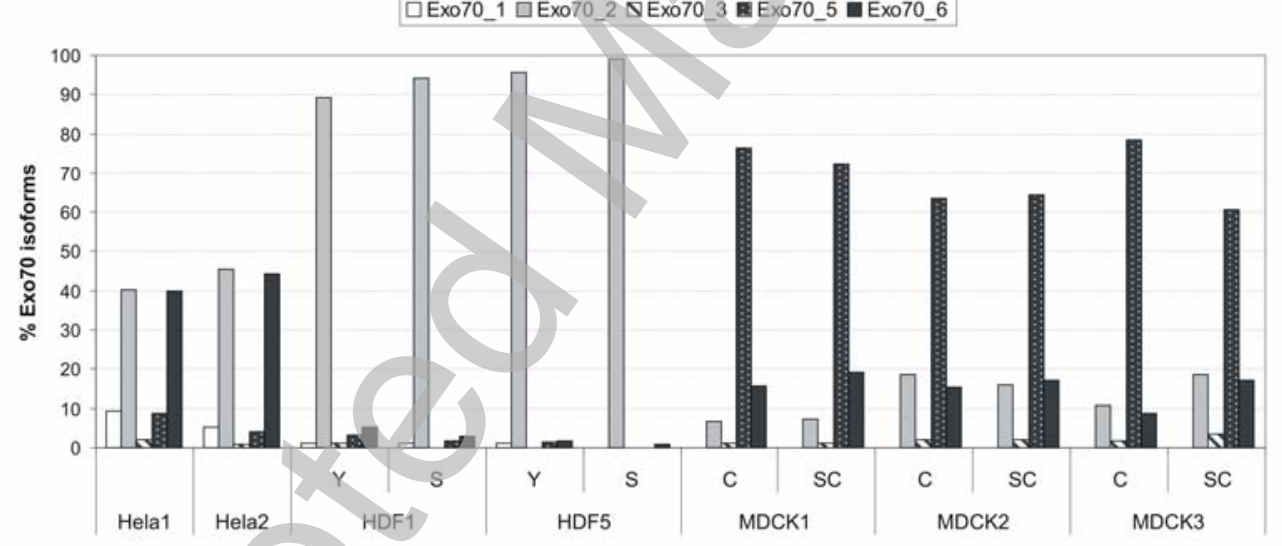

D

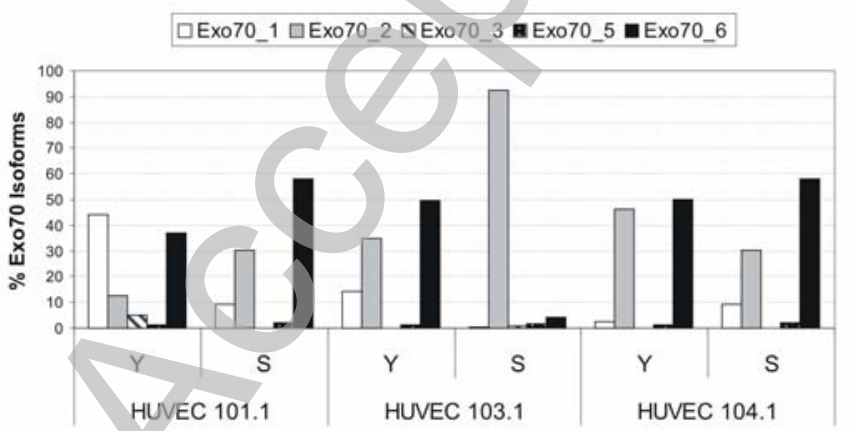

E

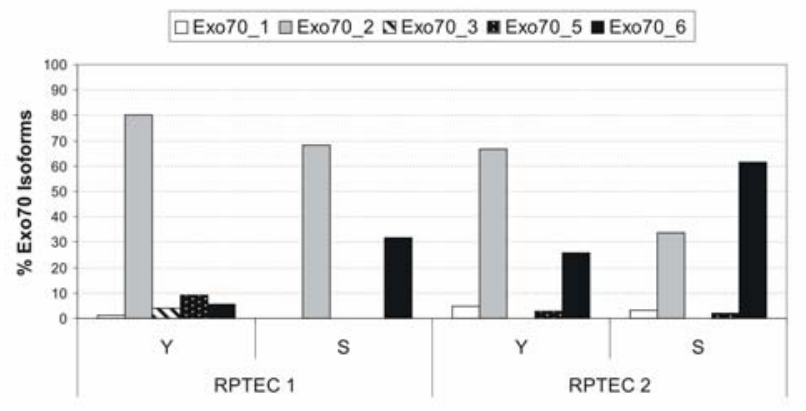

